\title{
Misallocation, Economic Growth, and Input-Output Economics
}

\author{
Charles I. Jones \\ Stanford GSB and NBER *
}

February 24, 2011

\begin{abstract}
One of the most important developments in the growth literature of the last decade is the enhanced appreciation of the role that the misallocation of resources plays in helping us understand income differences across countries. Misallocation at the micro level typically reduces total factor productivity at the macro level. Quantifying these effects is leading growth researchers in new directions, two examples being the extensive use of firm-level data and the exploration of input-output tables, and promises to yield new insights on why some countries are so much richer than others.
\end{abstract}

${ }^{*}$ Presented at the 10th World Congress of the Econometric Society in Shanghai, China. I am grateful to Antonio Ciccone, Bob Hall, John Fernald, and Pete Klenow for helpful comments and discussions. 


\section{Introduction}

One of the most important developments in the growth literature of the last decade is the enhanced appreciation of the role that the misallocation of resources plays in helping us understand income differences across countries. Given an economy's stock of physical capital, labor, human capital, and knowledge, the way in which those aggregate quantities of inputs are allocated across firms and industries — and even potentially within firms - determines the economy's overall level of production. The best allocation will maximize welfare and, in a sense that can be made precise, output itself in the long run. Other allocations result in lower levels of output and therefore show up in the aggregate as a lower level of total factor productivity (TFP).

In some broad sense, this is an old idea with many antecedents. In the real business cycle literature, for example, it is commonly appreciated that tax distortions or regulations may show up as TFP shocks. Chari, Kehoe and McGrattan (2007) follows in this tradition.

In the literature on growth and development, Restuccia and Rogerson (2008) explicitly analyze a model of misallocation among heterogeneous plants to quantify the effect on aggregate TFP. Banerjee and Duflo (2005) argue that the marginal product of capital differs widely among firms in India, potentially reducing overall output. Hsieh and Klenow (2009) present empirical evidence that misallocation across plants within 4-digit industries may reduce TFP in manufacturing by a factor of two to three in China and India. A large literature surrounding these papers considers various mechanisms through which misallocation can lead to income differences. ${ }^{1}$

This paper provides my own idiosynchratic perspective on misallocation and presents three basic points. First, I begin with an overview of misallocation. A simple toy model illustrates how misallocation can reduce TFP, and I outline several questions related to misallocation that might be considered in future research.

\footnotetext{
${ }^{1}$ Examples include Easterly (1993), Parente and Prescott (1999), Caselli and Gennaioli (2005), Lagos (2006), Alfaro, Charlton and Kanczuk (2008), Buera and Shin (2008), Guner, Ventura and Xu (2008), La Porta and Shleifer (2008), Bartelsman, Haltiwanger and Scarpetta (2009), Epifani and Gancia (2009), Peters (2009), Vollrath (2009), Midrigan and Xu (2010), Moll (2010), and Syverson (2010).
} 
Second, I suggest one way in which the effects of misallocation can be amplified: through the input-output structure of the economy. Because the outputs of many firms are used as the inputs of other firms, the effects of misallocation can be amplified. Finally, I provide an overview of the input-output structure of the United States and 34 other economies, albeit at a fairly high level of aggregation. In addition to supporting the basic point that the amplification associated with input-output economics can be quantitatively important, this overview suggests what I think is a remarkable similarity in the input-output structures of diverse economies. Understanding whether this really is the case, why it may be so, and what implications it entails is another useful area for future research.

\section{Misallocation}

This section provides an overview of the consequences of the misallocation of resources.

\subsection{Misallocation and TFP}

We begin by presenting a simple example that illustrates the basic point of the misallocation literature: misallocation reduces TFP.

Consider an economy in which the two key produced goods are steel and lattes:

$$
\begin{array}{lc}
\text { Production: } & X_{\text {steel }}=L_{\text {steel }}, \quad X_{\text {latte }}=L_{\text {latte }} \\
\text { Resource constraint: } & L_{\text {steel }}+L_{\text {latte }}=\bar{L} \\
\text { GDP (aggregation): } & Y=X_{\text {steel }}^{1 / 2} X_{\text {latte }}^{1 / 2}
\end{array}
$$

One unit of labor can produce either a unit of steel or a cup of latte. The economy is endowed with $\bar{L}$ units of labor. And we assume lattes and steel combine in a Cobb-Douglas fashion to generate a final good. This last equation could be replaced by a utility function, but then one would have to specify prices in order to aggregate the two goods; the approach here is simpler. 
Obviously, the only allocative decision that has to be made is how much labor to employ producing steel versus lattes. Let $x \equiv L_{\text {steel }} / \bar{L}$ denote the allocation of labor. This could be determined by perfectly competitive markets, by a social planner, by markets distorted by taxes, or in any number of different ways.

Solving for GDP given the allocation yields

$$
Y=A(x) \bar{L}
$$

where TFP, $A(x)$, is given by

$$
A(x)=\sqrt{x(1-x)}
$$

These two equations summarize in a simple way one of the key points of the recent literature on misallocation: the misallocation of resources reduces TFP. As is clear given the symmetry of the setup, the optimal allocation of labor in this simple economy features $x^{*}=1 / 2$. Any departure from this allocation — putting either too little or too much labor into making steel — reduces TFP and therefore GDP. More generally, if the exponents in the production function were $\sigma$ and $1-\sigma$ instead of $1 / 2$, then TFP would simply be $A(x)=x^{\sigma}(1-x)^{1-\sigma}$; this expression will be useful later. The effects of misallocation are shown graphically in Figure 1.

This figure illustrates another key point: small departures from the optimal allocation of labor have tiny effects on TFP (an application of the envelope theorem), but significant misallocation can have very large effects. Given the large income differences that we see across countries, this possibility is appealing.

However, more careful consideration of Figure 1 indicates that this simple model has what may be an important limitation: in the presence of significant misallocation, a small improvement in the allocation of resources will have a large impact on TFP.

Contrast this with a hypothetical example like that in Figure 2. The dashed line in the figure repeats the effect of misallocation on TFP from Figure 1, while the new solid line depicts an alternative. It seems to me that the alternative better captures the world we live in. As before, small misallocation has small effects and large mis- 
Figure 1: Misallocation Reduces TFP

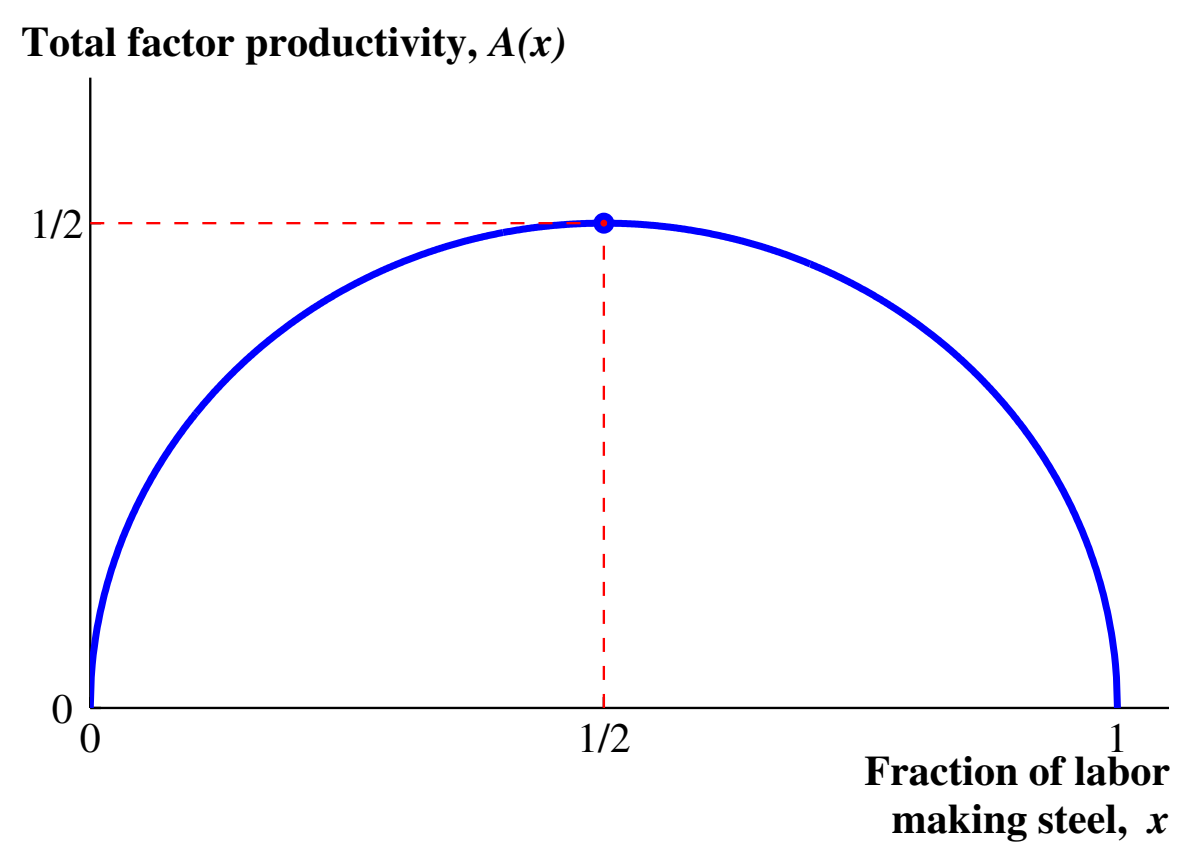

allocation has large effects. Now, however, an intermediate degree of misallocation can have large effects as well (e.g. if the allocation of labor has $x=1 / 4$, TFP is less than $1 / 4$ rather than larger than $1 / 4$ ). Moreover, with a large degree of misallocation, the effect on TFP of an improved allocation of resources is small: reforms in many cases would have small effects. Growth miracles would be less common in the second world and would be more likely to occur among countries with an intermediate degree of distortions than a large degree of distortions. This kind of structure may even help explain the "twin peaks" structure of the world income distribution emphasized by Quah (1996).

One of the challenges going forward in models of misallocation is - perhaps - to ensure that they capture some of the features of Figure 2 rather than some of the limitations in Figure 1. Jones (2011) explores the possibility that the O-ring style complementarity of Kremer (1993) may help in this regard.

This simple example is useful in illustrating how misallocation reduces TFP, but it fails to capture one of the key points emphasized in the recent literature on mis- 
Figure 2: An Alternative Model of Misallocation?

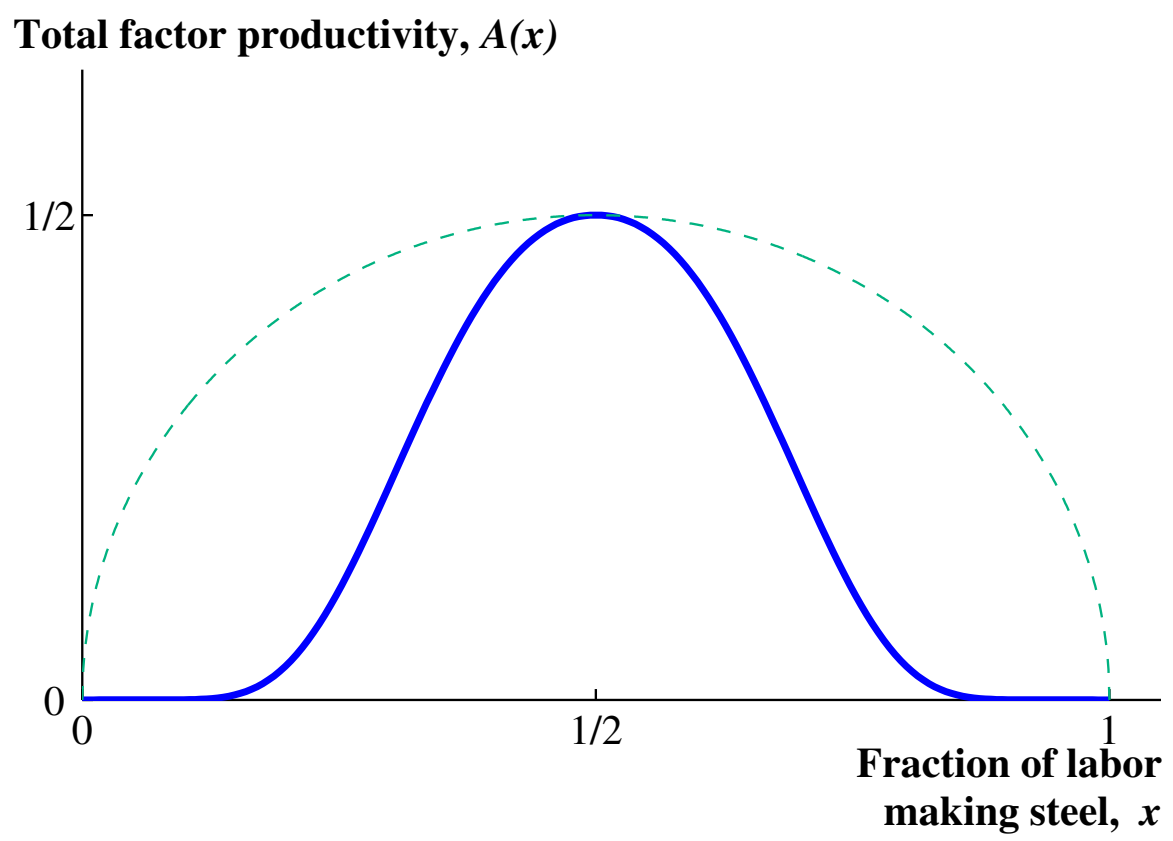

allocation. In the example, misallocation is across sectors: we may have too much or too little steel relative to what is optimal. In contrast, the recent literature often emphasizes misallocation at a more microeconomic level: within the steel sector, there are some plants that are good at making steel and others that are less good. Misallocation may involve giving the less efficient plants too many resources. This within sector misallocation is prominently emphasized by Foster, Haltiwanger and Syverson (2008) and Hsieh and Klenow (2009), for example. Clearly both kinds of misallocation (across and within sectors) can be important, and a very interesting, open question in the literature is determining the relative (and absolute) importance of each.

One might even push this insight further: Why are some plants more productive than others? Maybe because of the misallocation of resources within plants. Organizing a plant and producing output involve an enormous number of decisions, and these decisions may be distorted or made incorrectly because of misallocation: maybe the plant manager is not the best person for the job (Caselli and Gennaioli, 
2005), maybe the most talented workers within the plant are not promoted to the appropriate positions, maybe the incentives for the workers to produce efficiently are not present (Lazear, 2000), maybe unionization and job protection leads the firm to use too much labor inappropriately (Schmitz, 2005) and so on.

\subsection{Key Questions}

At some basic level, there are only two fundamental reasons for income differences across countries in the long run. Either economies have different production possibilities or they have different allocations. In the case of production possibilities, once we have endogenized ideas, the only remaining reason for differences is geographic. Maybe some pieces of land are more conducive to production than others. While there is probably something to this explanation, my current understanding is that these effects are small relative to the large income differences we see across countries. Probably the single most persuasive evidence on this point is the classic Mancur Olson (1996) argument: the large income difference that has emerged between North and South Korea over the last half century, for example, is surely not due to geography. ${ }^{2}$

This leaves differences in the allocation of resources to explain the bulk of income differences across countries. Given the production possibilities, allocations can then differ for two reasons: differences in preferences and misallocation. Again, there is probably something to the preference story (this seems like a plausible part of the explanation for the difference between the European and American allocation of resources). But at some basic level, people are people and any difference in preferences is probably itself an endogenous outcome.

This argument, then, suggests that all that is left, fundamentally, to explain differences in incomes across countries is misallocation, working both through traditional inputs like capital and labor and also through ideas. Income differences across countries result almost entirely from the misallocation of resources.

And yet to say misallocation is everything is perhaps not to say very much after

\footnotetext{
${ }^{2}$ Obviously, there is a large literature debating this question; for example, see Gallup, Sachs and Mellinger (1999) and Acemoglu, Johnson and Robinson (2002).
} 
all. In particular, three additional questions seem pertinent:

1. What is the nature of the misallocation? Are certain inputs misallocated more than others? Is the misallocation related to ideas special in any way relative to the misallocation of traditional inputs? How significant is misallocation within sectors or between sectors or even within plants? How much misallocation is there in the richest countries?

2. How precisely does the misallocation of resources lead to 50-fold income differences? A simple version of this question is illustrated by the differences we saw back in Figures 1 and 2. In the first case, large income differences required extreme forms of misallocation, and small improvements in the allocation of resources would have large effects on income. In the second, neither of these points is necessarily true. Why does a given amount of misallocation lead to such large income differences? And why are income differences across countries generally rising over time?

3. Why is there misallocation, and what can be done about it? This last question takes us into the realm of political economy. The literature on political economy and growth/development has been extremely active in the last decade; see Acemoglu, Johnson and Robinson (2005) for an excellent overview. The state-of-the-art in that literature suggests that misallocation is the equilibrium outcome of a political process interacting with institutions and the distribution of resources (including physical capital, human capital, ideas, and natural resources). It is, evidently, not in the economic interests of the ruling elite to improve the allocation of resources, despite the potentially enormous increase in the size of the economic pie that is possible in the long run.

The distinction between Figures 1 and 2 is helpful in this respect and illustrates the important interaction that occurs between the production possibilities of the economy and the political process. In Figure 1 it is harder to understand why improvements in the allocation of resources would not take place in the most distorted countries because the immediate gains are so large. Such failures are easier to comprehend in an economy like Figure 2, where the im- 
mediate gains may be much smaller.

The remainder of this paper takes a much narrower focus and explores one dimension of these key questions about misallocation. In particular, it focuses on the production possibilities and seeks to understand why a given amount of misallocation can lead to large income differences rather than small income differences.

\section{Input-Output Economics}

Modern economies involve very sophisticated input-output structures. Goods like electricity, financial services, transportation, information technology and healthcare are both inputs and outputs. A wide range of intermediate goods are used to produce most goods in the economy, and these goods in turn are often used as intermediates.

Despite our intuitive recognition of this point, standard models of macroeconomics and economic growth typically ignore intermediate goods. ${ }^{3}$ The conventional wisdom seems to be that as long as we are concerned about overall valueadded (GDP) in the economy, we can specify the model entirely in terms of valueadded and ignore intermediate goods. Hence the neoclassical growth model.

This conventional wisdom is incorrect, and the remainder of this paper explores some of the implications of the input-output structure of the economy for economic growth and development.

The first insight that emerges from thinking about intermediate goods is that they are very similar to capital. In fact, the only difference between intermediate goods and capital is one of short-run timing: intermediate goods can be installed more quickly than capital and "depreciate" fully during the course of production, while capital takes a bit longer to install and only partially depreciates during production. From the point of view of the long run - the perspective relevant in most of this paper - intermediate goods and capital are essentially the same. In particular, both are produced factors of production.

\footnotetext{
${ }^{3}$ Of course, there is a significant literature of exceptions; these will be discussed below.
} 
The key implications of intermediate goods for economic growth, development, and macroeconomics arise from seeing them as another form of capital. It has long been recognized that the share of capital in production is a fundamental determinant of the quantitative predictions of macro models. When the capital share is $1 / 3$, the intrinsic propogation mechanism of the neoclassical growth model is weak, convergence to the steady state is rapid, and the model generates a small multiplier on changes in productivity or the investment rate. In contrast, when the capital share is higher, like $2 / 3$, these deficiencies are largely remedied. A fairly large portion of the literature on economic growth can be viewed as an attempt to justify using a (broad) capital share of $2 / 3$ when the data for (narrow) capital loudly proclaim that the right number empirically is only $1 / 3 .{ }^{4}$

As documented carefully below, the intermediate goods share of gross output is about $1 / 2$ across a large number of countries. The share of capital in value-added is about $1 / 3$, so its share in gross output is $1 / 6$. Combining these two kinds of capital, the share of capital-like goods in gross output is our magic number, $1 / 2+1 / 6=$ $2 / 3$. Incorporating intermediate goods into macroeconomic models, then, has the potential to help us understand a range of economic phenomenon, including the propogation of business cycle shocks and the speed of transition dynamics. These applications will not be explored here. Instead, the main application in this paper will be to the puzzle of understanding why misallocation leads some countries to be 50 times richer than others, as opposed to only 10 times richer.

We begin by providing a simple example to illustrate how and why intermediate goods lead to large multipliers. In this example, a single final output good is used as the single intermediate good in the economy, so the input-output structure is very simple. Next, we build an $N$-sector model of economic activity, where each sector uses the outputs from the other sectors as intermediate goods. This model is very

\footnotetext{
${ }^{4}$ For examples of these points in various contexts, see Rebelo (1991), Mankiw, Romer and Weil (1992), Cogley and Nason (1995), and Chari, Kehoe and McGrattan (1997). Mankiw, Romer and Weil (1992) make many of these points, adding human capital to boost the capital share. Chari, Kehoe and McGrattan (1997) introduced “organizational capital” for the same reason. Howitt (2000) and Klenow and Rodriguez-Clare (2005) consider the accumulation of ideas, another produced factor. More recently, Manuelli and Seshadri (2005) and Erosa, Koreshkova and Restuccia (2010) have resurrected the human capital story in a more sophisticated fashion.
} 
similar to the original multi-sector business cycle model of Long and Plosser (1983). The only technological difference is that we include international trade, allowing sectors to import intermediate goods from abroad. The substantive difference is in the application to economic growth and development.

Finally, we connect this model to the wealth of input-output data that exist. Data from 35 countries - including not only the currently rich countries but also Argentina, Brazil, China, and India - allows us to quantify the multiplier associated with the input-output structure of the economy.

Before continuing, it is worth noting that there is a very important branch of the economics literature that has studied the impact of intermediate goods. Historically, the input-output literature reigned in economics from the 1930s through the 1960s and is most commonly associated with Leontief (1936) and his followers. Hirschman (1958) emphasized the importance of sectoral linkages to economic development, which itself spawned a large literature. Hulten (1978) is also closely related, showing how intermediate goods should properly be included in growth accounting. More recently, the intermediate goods multiplier shows up most clearly in the economic fluctuations literature; see Long and Plosser (1983), Basu (1995), Horvath (1998), Dupor (1999), Conley and Dupor (2003), Gabaix (2005), and Basu, Fernald, Fisher and Kimball (2010). In the international trade context, Yi (2003) argues that tariffs can multiply up in much the same way when goods get traded multiple times during the stages of production. Ciccone (2002) is the first modern growth paper I know of to develop this insight, deriving a multiplier formula for a triangular input-output structure. Jones (2011) also emphasizes the importance of the intermediate goods multiplier, albeit for a relatively restrictive input-output structure. $^{5}$

\subsection{A Simple Example}

A simple example is helpful for understanding how intermediate goods generate a multiplier. Suppose gross output $Q_{t}$ is produced using capital $K_{t}$, labor $L_{t}$, and

\footnotetext{
${ }^{5}$ Other recent examples incorporating an input-output structure include Acemoglu, Ozdaglar and Tahbaz-Salehi (2010) and Arbex and Perobelli (2010).
} 
intermediate goods $X_{t}$.

$$
Q_{t}=\bar{A}\left(K_{t}^{\alpha} L_{t}^{1-\alpha}\right)^{1-\sigma} X_{t}^{\sigma}
$$

Gross output can be used for consumption or investment or it can be carried over to the next period and used as an intermediate good. To keep things simple, assume a constant fraction $\bar{x}$ is used as an intermediate good:

$$
X_{t+1}=\bar{x} Q_{t} .
$$

GDP in this economy is gross output net of spending on intermediate goods: $Y_{t} \equiv$ $(1-\bar{x}) Q_{t}$. In a steady state with no growth, it is easy to show that GDP will be given by

$$
Y_{t}=\mathrm{TFP} \cdot K_{t}^{\alpha} L_{t}^{1-\alpha}
$$

where

$$
\mathrm{TFP} \equiv\left(\bar{A} \bar{x}^{\sigma}(1-\bar{x})^{1-\sigma}\right)^{\frac{1}{1-\sigma}}
$$

TFP depends on the allocation of resources to intermediate goods. It will be maximized when $\bar{x}=\sigma$, which is the optimal spending share on intermediates. For any other spending share, however, TFP will be lower, and this effect will be amplified the higher is the intermediate goods share.

Going further, let's assume a constant fraction $\bar{s}$ of GDP is invested:

$$
\begin{aligned}
K_{t+1} & =\bar{s} Y_{t}+(1-\delta) K_{t}, \\
& =\bar{s}(1-\bar{x}) Q_{t}+(1-\delta) K_{t},
\end{aligned}
$$

Assume labor is exogenous and constant.

This model features a steady state, where the level of GDP per worker $y_{t} \equiv Y_{t} / L_{t}$ is

$$
y^{*} \equiv \frac{Y}{L}=\left(\bar{A} \bar{x}^{\sigma}(1-\bar{x})^{1-\sigma}\left(\frac{\bar{s}}{\delta}\right)^{\alpha(1-\sigma)}\right)^{\frac{1}{(1-\alpha)(1-\sigma)}} .
$$

A key implication of this result is that the effects of misallocation or basic productivity differences get multiplied. In particular, consider the simple allocation 
term $\bar{x}^{\sigma}(1-\bar{x})^{1-\sigma}$, familiar from our steel-and-latte economy. Now that the misallocation applies to a produced good, its effects are amplified: there is an exponent of $\frac{1}{(1-\alpha)(1-\sigma)}>1$ that applies to misallocation.

To see this more simply, observe that a $1 \%$ increase in productivity $\bar{A}$ increases output by more than $1 \%$ because of the multiplier $\frac{1}{(1-\alpha)(1-\sigma)}$. In the absence of intermediate goods $(\sigma=0)$, this multiplier is just the familiar $\frac{1}{1-\alpha}$ : an increase in productivity raises output, which leads to more capital, which leads to more output, and so on. The cumulation of this virtuous circle is $1+\alpha+\alpha^{2}=\frac{1}{1-\alpha}$.

In the presence of intermediate goods, there is an additional multiplier: higher output leads to more intermediate goods, which raises output (and capital), and so on. The overall multiplier is therefore $\frac{1}{(1-\alpha)(1-\sigma)}$. In fact, this multiplier can also be written as $\frac{1}{1-\beta}$, where $\beta \equiv \sigma+\alpha(1-\sigma)$ is the total factor share of produced goods in gross output, capital and interemediates here.

Quantitatively, the addition of intermediate goods has a large effect. For example, consider the multipliers using conventional parameter values, a capital exponent of $\alpha=1 / 3$ and an intermediate goods share of gross output of $\sigma=1 / 2$. In the absence of intermediate goods the multiplier is $\frac{1}{1-\alpha}=3 / 2$, and a doubling of $\bar{A}$ raises output by a factor of $2^{3 / 2}=2.8$. But with intermediate goods, the multiplier is $\frac{1}{(1-\alpha)(1-\sigma)}=\frac{3}{2} \cdot 2=3$, and a doubling of $\bar{A}$ raises output by a factor of $2^{3}=8$. As discussed in Jones (2011), if we think of the standard neoclassical factors (like $\bar{s}$ in the example) as generating a 4-fold difference in incomes across rich and poor countries, then this 2-fold difference in TFP leads to an 11.3-fold difference in the model with no intermediate goods, but to a 32-fold difference once intermediate goods are taken into account, close to what we see in the data. ${ }^{6}$

The deeper question in this paper is whether this multiplier carries over into a model with a rich and realistic input-output structure. Perhaps the input-output

\footnotetext{
${ }^{6} \mathrm{An}$ implication of this reasoning that is worthy of further exploration is related to transition dynamics. A puzzle in the growth literature is why speeds of convergence are so slow, on the order of $2 \%$ per year; see Hauk and Wacziarg (2004) for a recent summary of the evidence. The standard neoclassical growth model with a capital share of $1 / 3$ leads to a speed of convergence of about $7 \%$ per year. The presence of intermediate goods would slow this rate down, just as it raises the multiplier. (A difficulty in quantifying this effect is the question of how long it takes to produce and use intermediate goods: one week, one month, or one year? That is, how long is a period?)
} 
structure in practice does not lead to these large feedback effects. Or perhaps importing intermediate goods dilutes the multiplier substantially in practice. In fact, the remainder of this paper shows that these concerns are not important in practice. The simple "one over one minus the intermediate goods share" formula suggested by this example turns out to be a very good approximation to the true input-output multiplier in modern economies. Moreover, we introduce distortions explicitly and show how this same multiplier applies to misallocation.

\section{Preliminary Exploration of a Full Input-Output Model}

Assume the economy consists of $N$ sectors. Each sector uses capital, labor, domestic intermediate goods, and imported intermediate goods to produce gross output. In turn, this output can be used for final consumption or as an intermediate good in production.

Given this general picture, we specialize to a particular structure with two goals in mind: analytic tractability and obtaining a model that can be closely connected to the rich input-output data. To these ends, the model augments the original Long and Plosser (1983) business cycle model, based on Cobb-Douglas production functions, by embedding it in a model with trade.

We begin by describing the economic environment and then allocate resources using a competitive equilibrium with distortions.

\subsection{The Economic Environment}

Each of the $N$ sectors produces with the following Cobb-Douglas technology:

$$
Q_{i}=A_{i}\left(K_{i}^{\alpha_{i}} H_{i}^{1-\alpha_{i}}\right)^{1-\sigma_{i}-\lambda_{i}} \underbrace{d_{i 1}^{\sigma_{i 1}} d_{i 2}^{\sigma_{i 2}} \cdot \ldots \cdot d_{i N}^{\sigma_{i N}}}_{\text {domestic IG }} \underbrace{m_{i 1}^{\lambda_{i 1}} m_{i 2}^{\lambda_{i 2}} \cdot \ldots \cdot m_{i N}^{\lambda_{i N}}}_{\text {imported IG }}
$$

where $i$ indexes the sector. $A_{i}$ is an exogenous productivity term, which itself is the product of aggregate productivity $A$ and sectoral productivity $\eta_{i}: A_{i} \equiv A \eta_{i} . K_{i}$ and $H_{i}$ are the quantities of physical and human capital used in sector $i$. Two kinds of 
intermediate goods are used in production: $d_{i j}$ is the quantity of domestic good $j$ used by sector $i$, and $m_{i j}$ is the quantity of the imported intermediate good $j$ used by sector $i$. (We assume imported intermediate goods are different, so that they are not perfect substitutes; this fits with the empirical fact that countries both import and produce intermediate goods in narrow 6-digit categories.) We abuse notation by assuming there are $N$ different intermediate goods that can be imported and by indexing these by $j$ as well. The parameter values in this production function satisfy $\sigma_{i} \equiv \sum_{j=1}^{N} \sigma_{i j}$ and $\lambda_{i} \equiv \sum_{j=1}^{N} \lambda_{i j}$ and $0<\alpha_{i}<1$, so the production function features constant returns to scale.

Each domestically produced good can be used for final consumption, $c_{j}$, or can be used as an intermediate good:

$$
c_{j}+\sum_{i=1}^{N} d_{i j}=Q_{j}, \quad j=1, \ldots, N
$$

Rather than specifying a utility function over the $N$ different consumption goods and performing a formal national income accounting exercise, it is more convenient to aggregate these final consumption goods into a single final good through another log-linear production function:

$$
Y=c_{1}^{\beta_{1}} \cdot \ldots \cdot c_{N}^{\beta_{N}}
$$

where $\sum_{i=1}^{N} \beta_{i}=1$.

This aggregate final good can itself be used in one of two ways, as consumption or exported to the rest of the world:

$$
C+X=Y \text {. }
$$

It is these exports that pay for the imported intermediate goods. We think of this (static) model as describing the long-run steady state of a model, so we impose balanced trade:

$$
X=\sum_{i=1}^{N} \sum_{j=1}^{N} \bar{p}_{j} m_{i j}
$$


where $\bar{p}_{j}$ is the exogenous world price of the imported intermediate goods.

Finally, we assume fixed, exogenous supplies of physical and human capital; the effects of endogenizing physical capital in the usual way are well-understood.

$$
\begin{aligned}
& \sum_{i=1}^{N} K_{i}=K, \\
& \sum_{i=1}^{N} H_{i}=H .
\end{aligned}
$$

\subsection{A Competitive Equilibrium with Misallocation}

To allocate resources in this economy, we will focus on a competitive equilibrium with distortions. As in Chari, Kehoe and McGrattan (2007), Hsieh and Klenow (2009), Lagos (2006), and Restuccia and Rogerson (2008), distortions at the micro (here sectoral) level can aggregate up to provide differences in TFP. For simplicity, we model these distortions as sector-specific reductions in revenue, denoted $\tau_{i}$. These distortions could literally be taxes, but they are better thought of as representing any kind of policy that favors one sector over another (regulations, special consideration for credit, and so on). The introduction of these exogenous sector-specific distortions should be understood as a reduced-form shortcut. Ideally, one would build a full microeconomic model where the distortions formally correspond to explicit regulations, capital market imperfections, market power, or theft. The insight developed here is that the misallocation associated with these distortions - whatever they are - gets amplified by the input-output structure of the economy.

Definition A competitive equilibrium with misallocation in this environment is a collection of quantities $C, Y, X, Q_{i}, K_{i}, H_{i}, c_{i}, d_{i j}, m_{i j}$ and prices $p_{j}, w$, and $r$ for $i=1, \ldots, N$ and $j=1, \ldots, N$ such that

1. $\left\{c_{i}\right\}$ solves the profit maximization problem of a representative firm 
in the perfectly competitive final goods market:

$$
\max _{\left\{c_{i}\right\}} c_{1}^{\beta_{1}} \cdot \ldots \cdot c_{N}^{\beta_{N}}-\sum_{i=1}^{N} p_{i} c_{i}
$$

taking $\left\{p_{i}\right\}$ as given.

2. $\left\{d_{i j}, m_{i j}\right\}, K_{i}, H_{i}$ solve the profit maximization problem of a representative firm in the perfectly competitive sector $i$ for $i=1, \ldots, N$ :

$$
\begin{gathered}
\max _{\left\{d_{i j}, m_{i j}\right\}, K_{i}, H_{i}}\left(1-\tau_{i}\right) p_{i} A_{i}\left(K_{i}^{\alpha_{i}} H_{i}^{1-\alpha_{i}}\right)^{1-\sigma_{i}-\lambda_{i}} d_{i 1}^{\sigma_{i 1}} d_{i 2}^{\sigma_{i 2}} \cdot \ldots \cdot d_{i N}^{\sigma_{i N}} m_{i 1}^{\lambda_{i 1}} m_{i 2}^{\lambda_{i 2}} \cdot \ldots \cdot m_{i N}^{\lambda_{i N}} \\
-\sum_{j=1}^{N} p_{j} d_{i j}-\sum_{j=1}^{N} \bar{p}_{j} m_{i j}-r K_{i}-w H_{i},
\end{gathered}
$$

taking $\left\{p_{i}\right\}$ as given $\left(\tau_{i}, A_{i}\right.$, and $\bar{p}_{j}$ are exogenous).

3. Markets clear

(a) $r$ clears the capital market: $\sum_{i=1}^{N} K_{i}=K$

(b) $w$ clears the labor market: $\sum_{i=1}^{N} H_{i}=H$

(c) $p_{j}$ clears the sector $j$ market: $c_{j}+\sum_{i=1}^{N} d_{i j}=Q_{j}$

4. Balanced trade pins down $X$ :

$$
X=\sum_{i=1}^{N} \sum_{j=1}^{N} \bar{p}_{j} m_{i j} .
$$

5. Production functions for $Q_{i}$ and $Y$ :

$$
\begin{gathered}
Q_{i}=A_{i}\left(K_{i}^{\alpha_{i}} H_{i}^{1-\alpha_{i}}\right)^{1-\sigma_{i}-\lambda_{i}} d_{i 1}^{\sigma_{i 1}} d_{i 2}^{\sigma_{i 2}} \cdot \ldots \cdot d_{i N}^{\sigma_{i N}} m_{i 1}^{\lambda_{i 1}} m_{i 2}^{\lambda_{i 2}} \cdot \ldots \cdot m_{i N}^{\lambda_{i N}} \\
Y=c_{1}^{\beta_{1}} \cdot \ldots \cdot c_{N}^{\beta_{N}} .
\end{gathered}
$$

6. Consumption is the residual:

$$
C+X=Y \text {. }
$$


Counting loosely, there are 12 equilibrium objects to be determined and 12 equations implicit in this equilibrium definition. Hiding behind the last equation is the fact that the revenues from distortions are assumed to be rebated lump sum to households. Because of balanced trade, however, there is no decision for households to make regarding final consumption $C$, and it is simply determined as the residual of final output less exports. ${ }^{7}$

\subsection{Solving}

In solving for the equilibrium of the model, it is useful to define some notation involving linear algebra. This is summarized in Table 1. Then the following proposition characterizes the equilibrium (all proofs are given in the appendix):

Proposition 1 (Solution for $Y$ and $C$ ) In the competitive equilibrium with misallocation, the solution for total production of the aggregate final good is

$$
Y=A^{\tilde{\mu}} K^{\tilde{\alpha}} H^{1-\tilde{\alpha}} \epsilon,
$$

where the following notation applies:

$$
\begin{aligned}
& \mu^{\prime} \equiv \frac{\beta^{\prime}(I-B)^{-1}}{1-\beta^{\prime}(I-B)^{-1} \lambda}, \quad(N \times 1 \text { vector of multipliers }) \\
& \tilde{\mu} \equiv \mu^{\prime} \mathbf{1} \\
& \tilde{\alpha} \equiv \mu^{\prime} \delta_{K} \\
& \omega \equiv \frac{\beta^{\prime} \omega_{c}+\beta^{\prime}(I-B)^{-1} \omega_{q}}{1-\beta^{\prime}(I-B)^{-1} \lambda} \\
& \log \epsilon \equiv \omega+\mu^{\prime} \bar{\eta} .
\end{aligned}
$$

Moreover, because trade is balanced, GDP for this economy is given by $C$, which equals

$$
C=Y\left(1-\sum_{i=1}^{N} \sum_{j=1}^{N}\left(1-\tau_{i}\right) \gamma_{i} \lambda_{i j}\right)
$$

\footnotetext{
${ }^{7}$ Given Walras' Law, this equation could be replaced by $C=w H+r K+T$, where $T$ is the lump sum rebate of the revenue obtained by the distortion; notice that all production is either consumed or exported.
} 
Table 1: Notation for Solving the Model

\begin{tabular}{|c|c|c|}
\hline Notation & $\begin{array}{c}\text { Typical } \\
\text { Element }\end{array}$ & Comment \\
\hline \multicolumn{3}{|c|}{ Matrices $(N \times N)$ : } \\
\hline$B$ & $\sigma_{i j}$ & The input-output matrix of intermediate good shares. \\
\hline $\bar{B}$ & $\left(1-\tau_{i}\right) \sigma_{i j}$ & $\begin{array}{l}\text { The matrix of intermediate good exponents, adjusted fo } \\
\text { distortions. }\end{array}$ \\
\hline$I$ & - & Identity matrix. \\
\hline \multicolumn{3}{|c|}{ Vectors $(N \times 1)$ : } \\
\hline 1 & 1 & Vector of ones. \\
\hline$\beta$ & $\beta_{i}$ & Vector of exponents in final goods production. \\
\hline$\gamma$ & $\gamma_{i}$ & $\gamma \equiv\left(I-\bar{B}^{\prime}\right)^{-1} \beta$; "Domar" shares: $\frac{p_{i} Q_{i}}{Y}=\gamma_{i}$ \\
\hline$\lambda$ & $\lambda_{i}$ & Vector of import shares, $\lambda_{i} \equiv \sum_{j=1}^{N} \lambda_{i j}$. \\
\hline$\delta_{K}$ & $\alpha_{i}\left(1-\sigma_{i}-\lambda_{i}\right)$ & Production elasticities for $K_{i}$ \\
\hline$\delta_{H}$ & $\left(1-\alpha_{i}\right)\left(1-\sigma_{i}-\lambda_{i}\right)$ & Production elasticities for $H_{i}$ \\
\hline$\theta_{K}$ & $\frac{\delta_{K i} \gamma_{i}}{\sum_{j=1}^{N}\left(1-\tau_{j}\right) \delta_{K j} \gamma_{j}}$ & Solution: $K_{i} / K=\left(1-\tau_{i}\right) \theta_{K i}$ \\
\hline$\theta_{H}$ & $\frac{\delta_{H i} \gamma_{i}}{\sum_{j=1}^{N}\left(1-\tau_{j}\right) \delta_{H j} \gamma_{j}}$ & Solution: $H_{i} / H=\left(1-\tau_{i}\right) \theta_{H i}$ \\
\hline$\omega_{K}$ & $\delta_{K i} \log \theta_{K i}$ & Sectoral allocation term for $K_{i}$ \\
\hline$\omega_{H}$ & $\delta_{H i} \log \theta_{H i}$ & Sectoral allocation term for $H_{i}$ \\
\hline$\omega_{d}$ & $\sum_{j=1}^{N} \sigma_{i j} \log \left(\sigma_{i j} \gamma_{i} / \gamma_{j}\right)$ & Sectoral allocation term for $d_{i j}$ \\
\hline$\omega_{m}$ & $\sum_{j=1}^{N} \lambda_{i j} \log \left(\lambda_{i j} \gamma_{i} / \bar{p}_{j}\right)$ & Sectoral allocation term for $m_{i j}$ \\
\hline$\omega_{q}$ & $\omega_{K i}+\omega_{H i}+\omega_{d i}+\omega_{m i}$ & Sum of allocation terms \\
\hline$\omega_{c}$ & $\log \left(\beta_{i} / \gamma_{i}\right)$ & Consumption allocation term \\
\hline $\bar{\eta}$ & $\log \left(\eta_{i}\left(1-\tau_{i}\right)\right)$ & Sectoral productivity, adjusted for distortions \\
\hline
\end{tabular}


There are several points of this proposition that merit discussion. First, and not surprisingly, our $N$-sector Cobb-Douglas model aggregates up to yield a CobbDouglas aggregate production function. More interestingly, aggregate TFP depends on both sectoral TFPs and the underlying distortions. This latter point requires digging into the $\epsilon$ term, where distortions then enter in two places. Distortions enter directly through $\bar{\eta}$, which is a vector of sectoral productivities, adjusted for distortion rates; this is the usual sense in which distortions "directly" affect productivity. Distortions also enter indirectly through the allocation terms, captured by $\omega$. We will return later to the effect of distortions.

The second result to note is the presence of the input-output multiplier, reflected by $\mu$. According to the proposition, this vector of multipliers is given by

$$
\mu^{\prime} \equiv \frac{\beta^{\prime}(I-B)^{-1}}{1-\beta^{\prime}(I-B)^{-1} \lambda}
$$

Let's break this down piece by piece, since it is one of the essential results of the paper.

The matrix $L \equiv(I-B)^{-1}$ is known as the Leontief inverse. The typical element $\ell_{i j}$ of this matrix can be interpreted in the following way: (ignoring trade for the moment) a $1 \%$ increase in productivity in sector $j$ raises output in sector $i$ by $\ell_{i j} \%$. This result takes into account all the indirect effects at work in the model. For example, raising productivity in the electricity sector makes banking more efficient and this in turn raises output in the construction industry. The Leontief inverse incorporates these indirect effects. (Notice that it is the matrix equivalent of $1 / 1-\sigma$.)

Multiplying this matrix by the vector of value-added weights in $\beta$ leads to $\beta^{\prime}(I-$ $B)^{-1}=\sum_{i=1}^{N} \beta_{i} \ell_{i j}$. That is, we add up the effects of sector $j$ on all the other sectors in the economy, weighting by their shares of value-added. The typical element of this multiplier matrix then reveals how a change in productivity in sector $j$ affects overall value-added in the economy.

This would be precisely correct if $\lambda_{i j}$ were zero - that is, in the absence of trade. In the presense of trade, this multiplier gets adjusted by the factor $1 /\left(1-\beta^{\prime}(I-\right.$ $B)^{-1} \lambda$ ). We will discuss this factor in more detail below, but for now it is enough to 
note that this factor is larger than one: trade strengthens the multiplier rather than attenuating it.

The elasticity of final output with respect to aggregate TFP is $\tilde{\mu} \equiv \mu^{\prime} 1$. That is, we add up all the multipliers in $\mu$ since an increase in aggregate TFP affects not just sector $j$ but all the sectors.

A final remark about Proposition 1 concerns the capital exponent in the aggregate production function, $\tilde{\alpha} \equiv \mu^{\prime} \delta_{K}$. Recall that $\delta_{K}$ is the vector of capital exponents $\alpha_{i}\left(1-\sigma_{i}-\lambda_{i}\right)$. The aggregate exponent is therefore a weighted average of the sectoral capital shares, where the weights depend on the intermediate good shares. This remark will make even more sense after the next proposition.

\section{Special Cases, To Build Intuition}

\subsection{The Multiplier in a Special Case}

The linear algebra formula is a useful theoretical result and will prove convenient when we apply the model to the rich input-output data that exists. However, analyzing a special case can be helpful in obtaining intuition for how the model works.

Consider the following special case. Suppose all sectors have the same cumulative elasticities of output with respect to domestic and imported intermediate goods, although the composition across sectors is allowed to vary. For example, one sector may use a lot of electricity and steel, while another sector uses a lot of financial services and information technology. The composition can vary across sectors, but suppose each sector spends 50 percent of its revenue on intermediate goods. What does the multiplier look like in a case like this?

The following proposition provides the answer. In fact, it allows for imported intermediate goods as well (where the overall share spent on these goods is the same in each sector):

Proposition 2 (Multiplier in a special case) Assume $\sigma_{i} \equiv \sum_{j=1}^{N} \sigma_{i j}=\hat{\sigma}$ and $\lambda_{i} \equiv$ $\sum_{j=1}^{N} \lambda_{i j}=\hat{\lambda}$ for all $i$, where $\hat{\sigma}$ and $\hat{\lambda}$ are positive scalars whose sum is less than one, 
and define $\bar{\sigma} \equiv \hat{\sigma}+\hat{\lambda}$ to be the total intermediate goods share. Then

$$
\frac{\partial \log Y}{\partial \log A}=\mu^{\prime} \mathbf{1}=\frac{\beta^{\prime}(I-B)^{-1} \mathbf{1}}{1-\beta^{\prime}(I-B)^{-1} \lambda}=\frac{1}{1-\bar{\sigma}} .
$$

This special case makes two general points about the model. First, the "sparseness" of the input-output matrix $B$ is not especially important. For example, our special case includes a "clock" structure, where every sector uses as an input only the good produced by the sector above it. It also includes the case where every sector uses only its own output. In both of these cases, the input-output matrix is very sparse, with zeros almost everywhere. Yet the overall multiplier remains equal to one over one minus the intermediate goods share. This special case suggests that if the overall intermediate goods share is about $1 / 2$, we shouldn't be surprised to find a multiplier of about 2 . This intuition will be confirmed in the next section when we turn to quantitative results.

The second key point made in this proposition is that the intuition that imports would dilute the multiplier is a red herring. In fact, there is no dilution at all: in the proposition, it is the overall intermediate goods share $\bar{\sigma} \equiv \hat{\sigma}+\hat{\lambda}$ that matters for the multiplier, and the composition between domestic and imported goods is completely irrelevant.

Why is this the case? The answer is that we have imposed balanced trade in our (long run) model. Therefore exports are used to "produce" imports. A higher productivity in the domestic computer chip sector raises overall exports, which in turn increases imports, so the virtuous circle is not broken by the presence of trade. ${ }^{8}$

\subsection{Symmetry and Distortions}

Our second special case allows us to study the multiplier associated with distortions. First, we consider a world where the intermediate good shares of production are the same in every sector and there is a symmetric distortion at rate $\tau_{i}=\bar{\tau}$. In

\footnotetext{
${ }^{8}$ This assumption of balanced trade is the key difference that makes the intuition from the Keynesian business cycle model inappropriate. In the business cycle context, an increase in exports leads to a trade surplus and does not increase imports.
} 
Figure 3: Consumption versus the Average Distortion, $\bar{\tau}$

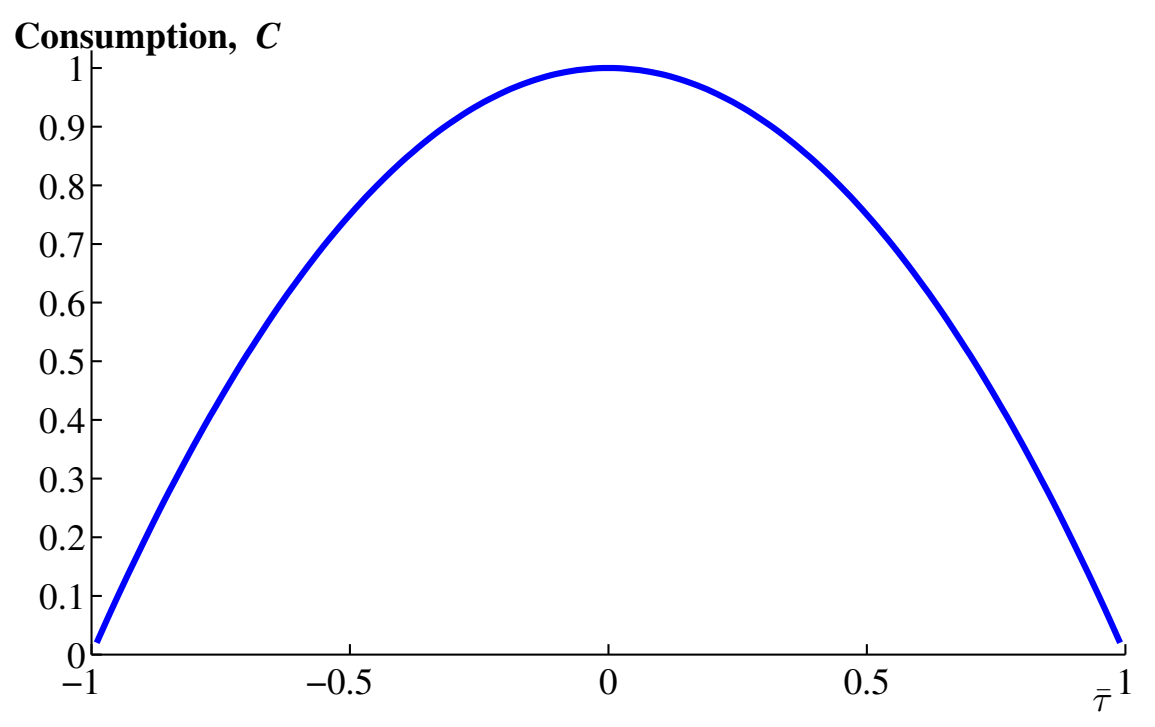

Note: This example is drawn for $\bar{\sigma}=1 / 2$. Notice the similarity to Figure 1 .

this case, GDP in the economy is given by the following proposition:

Proposition 3 (Symmetry and Distortions) Suppose $\sigma_{i j}=\hat{\sigma} / N, \lambda_{i j}=\hat{\lambda} / N, \beta_{i}=$ $1 / N, \alpha_{i}=\alpha$, and $\tau_{i}=\bar{\tau}$. Then

$$
\log C=\text { Constant }+\frac{\bar{\sigma}}{1-\bar{\sigma}} \log (1-\bar{\tau})+\log (1-\bar{\sigma}(1-\bar{\tau}))
$$

where $\bar{\sigma} \equiv(\hat{\sigma}+\hat{\lambda})$ denotes the total intermediate goods share, and Constant is a collection of terms that do not depend on $\bar{\tau}$. Moreover, consumption is an inverse- $U$ shaped function of the distortion rate, with a peak that occurs at $\bar{\tau}=0$.

An example of this proposition is shown in Figure 3. Notice that the effect of a change in the distortion rate on GDP depends essentially on $\bar{\sigma}$. If there are no intermediate goods in this economy, output distortions have no effect. This is because the distortions here represent a violation of the Diamond and Mirrlees (1971) dictum of "no taxation of intermediate goods." In our (current) setup, $K$ and $H$ are 
non-produced factors, so a symmetric tax does not distort the allocation of capital. ${ }^{9}$

The key distortion is between consumption and intermediate goods. A good that gets consumed suffers the distortion only once when the good is produced; a good that is used as an intermediate gets distorted when it is first produced then again when it is used as an intermediate. Since a constant fraction of output is consumed and the rest is used as an intermediate good, this process suffers from the vicious cycle of the multiplier.

Symmetric distortions affect GDP through the two terms in equation (17). The first term is the direct effect, where distortions enter the model very much like productivity: recall that both $1-\tau_{i}$ and $A_{i}$ are subject to the multiplier effect through the $\epsilon$ term in Proposition 1. The second term mitigates this effect somewhat and captures the indirect effect whereby higher distortions raise consumption (by reducing the purchase of intermediate goods).

\subsection{Symmetry with Random Distortions}

Our final special case allows us to consider variation in distortions across sectors. Suppose everything in the model other than distortions is symmetric, and allow distortions to be a log-normally distributed random variable:

Proposition 4 (Symmetry with Random Distortions) Suppose $\sigma_{i j}=\hat{\sigma} / N, \lambda_{i j}=\hat{\lambda} / N$, and $\beta_{i}=1 / N$, and let $\bar{\sigma} \equiv \hat{\sigma}+\hat{\lambda}$. Assume $\log \left(1-\tau_{i}\right) \sim N\left(\theta, v^{2}\right)$ and let $1-\bar{\tau} \equiv e^{\theta+\frac{1}{2} v^{2}}$ reflect the average distortion. Then

$$
\begin{aligned}
\operatorname{plim}_{N \rightarrow \infty} \log C= & \text { Constant }+\frac{\bar{\sigma}}{1-\bar{\sigma}} \cdot(1-\bar{\tau}) \\
& +\log (1-\bar{\sigma}(1-\bar{\tau}))-\frac{1}{1-\bar{\sigma}} \cdot \frac{1}{2} \cdot v^{2}
\end{aligned}
$$

where Constant is a collection of terms that do not depend on $\theta$ or $v^{2}$. Moreover, consumption is maximized when there are no distortions.

In terms of the mean effect of distortions, this result is identical to the previous one. Now, however, we have an additional result related to the variance of distor-

\footnotetext{
${ }^{9}$ See also Solow (1986).
} 
Figure 4: Consumption versus the Standard Deviation of Distortions

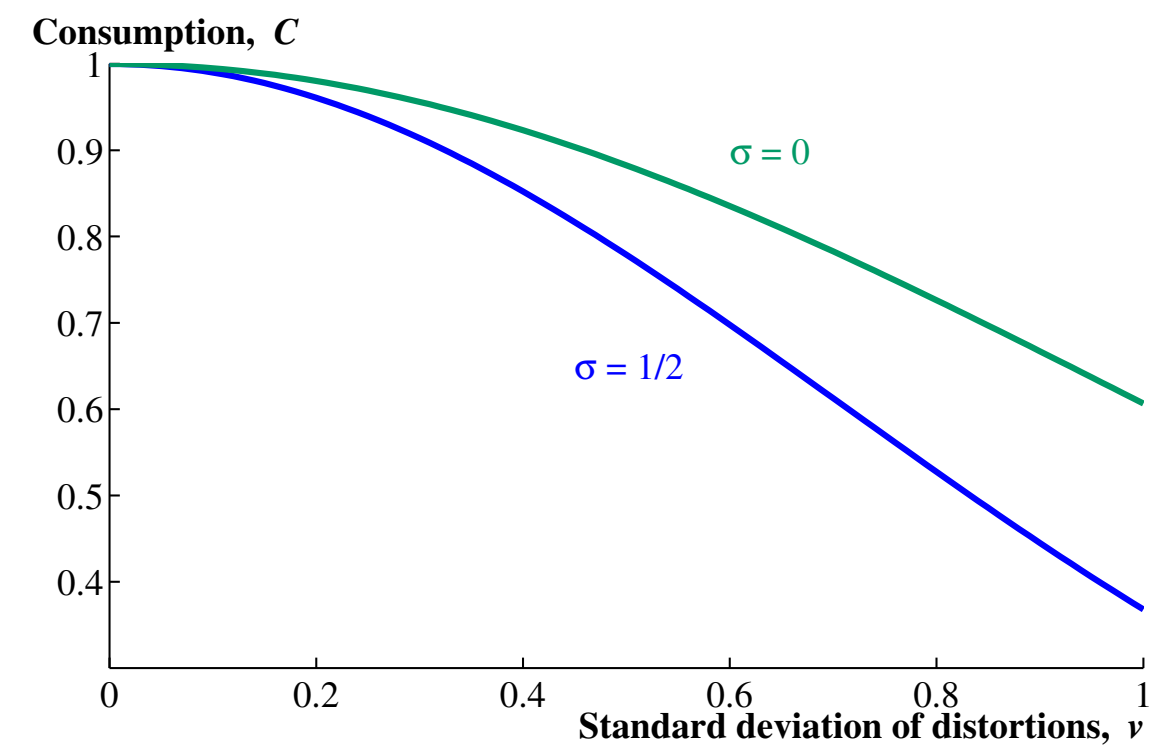

Note: This example is drawn for $\bar{\tau}=0$.

tions across sectors. In particular, a higher variance of distortions reduces GDP, even in the absence of intermediate goods, since random distortions will distort the allocation of capital and labor across sectors. However, the variance term itself is subject to the now-familiar multiplier effect associated with $1 / 1-\bar{\sigma}$. A higher variance of distortions is more costly in an economy with intermediate goods. This makes sense: the first best in this economy is to have no distortions. Either a constant tax or a random tax distorts the allocation of resources and reduces GDP. The magnitude of the distortion depends on the Diamond-Mirrlees effect: how important intermediate goods are in production. An example is illustrated in Figure 4.

\subsection{Random Distortions with a General I-O Structure}

So far, I have lacked the right combination of time, talent, and insight to derive a more general result for the effect of log-normal distortions in the presence of the full input-output structure, though I suspect that good results are possible along these 
lines. The intuition from the previous propositions strongly suggests that something like the general multiplier $\tilde{\mu}$ will continue to play a crucial role. For the empirical applications that follow, I will therefore focus on this general multiplier.

\section{Quantitative Analysis}

We now turn to the rich input-output data that exists, both for the United States and for many other countries. This data allows us to calculate aggregate and sectoral multipliers and to study the effect of sectoral distortions on aggregate GDP. First, we use the six-digit level data available from the U.S. Bureau of Economic Analysis for the United States in 1997. Then we turn to the OECD Input-Output Database, which contains data for 48 industries and 35 countries.

\subsection{The U.S. Input-Output Data, 480 Industries}

Figure 5 shows something very close to the $B$ matrix for the United States, using the 480 commodities in the BEA's 1997 benchmark input-output data. Actually, we plot the matrix of $\sigma_{i j}+\lambda_{i j}$ instead, so that the entries show the overall exponents on intermediate goods used in producing each of the 480 goods. A contour plot method is used, showing only those shares greater than $2 \%, 4 \%$, and $8 \%$.

Three points stand out in the figure. First, there is a strong diagonal. Second, the matrix is relatively sparse. Finally, there are a few key exceptions to this sparseness: a few key goods are used by a large number of industries in a significant way. These include wholesale trade, trucking, management of companies, real estate, paperboard products, and iron and steel mills.

Table 2 reports some basic statistics of the U.S. input-output matrix that help put these visual conclusions in context. Even though the diagonal elements were im-

portant visually, the table makes the point that these elements are typically small: the mean of them is only $3.3 \%$ and the median is only $1.0 \%$. This is true despite the fact that the typical industry pays a large share of its gross output to intermediate goods: $56.4 \%$ at the mean. The industry at the 75 th percentile pays out about 
Figure 5: The U.S. Input-Output Matrix, 1997 (480 Industries)

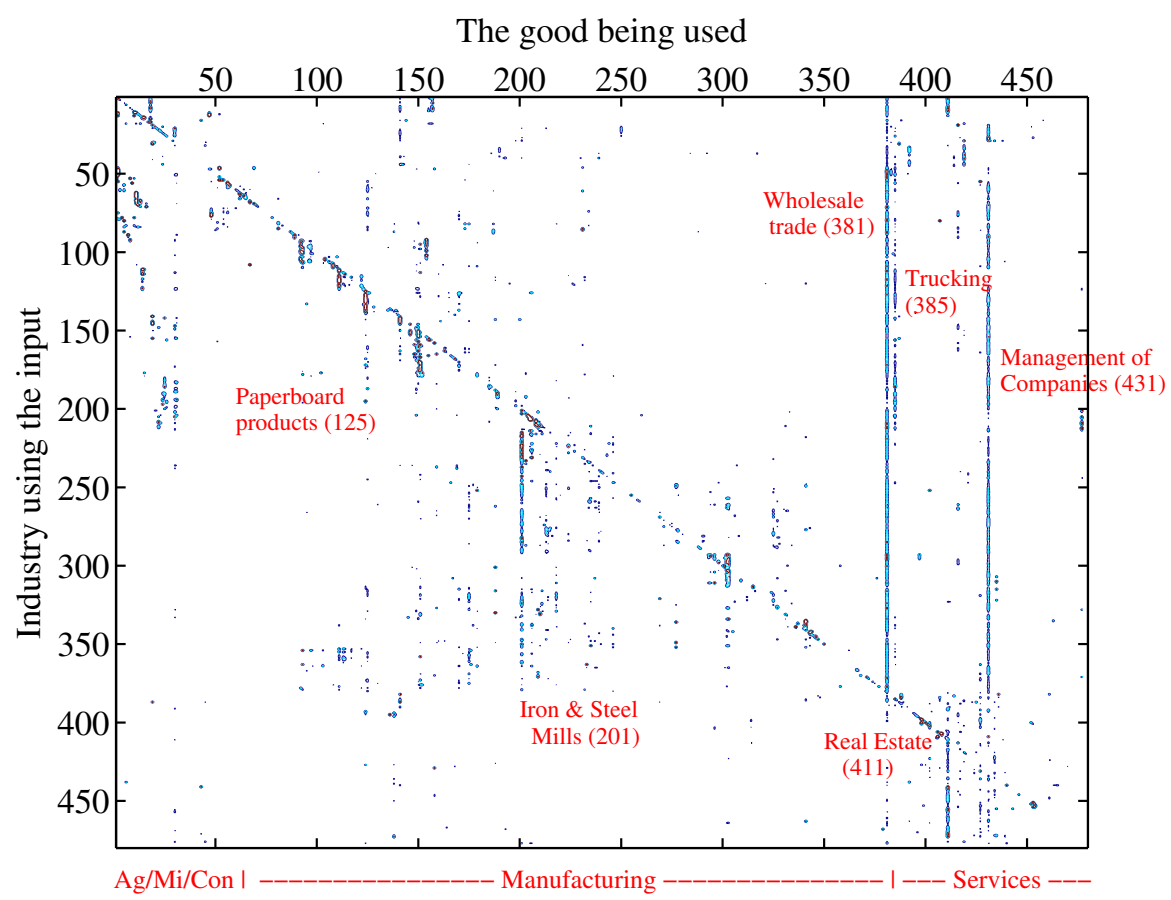

Note: The plot shows the matrix $\left[\sigma_{i j}+\lambda_{i j}\right]$, that is, the matrix of intermediate good shares for 480 industries. A contour plot method is used, showing only those shares greater than $2 \%, 4 \%$, and $8 \%$. Source: BEA 1997 Input-Output Benchmark data. 
Table 2: Statistics of the U.S. Input-Output Matrix, 1997 (480 Industries)

Properties of the diagonal elements

Mean:

0.033

75th percentile:

0.045

50th percentile:

0.010

25th percentile:

0.002

Fraction of all elements that are

equal to zero:

0.510

below 0.1 percent:

0.882

below 0.5 percent:

0.958

below 1.0 percent:

0.979

below 5.0 percent:

0.996

above 10 percent:

0.0013

above 20 percent:

0.0004

above 50 percent:

0.0000

Mean of $\sigma_{i}+\lambda_{i}$ :

0.564

75th percentile:

0.666

50th percentile:

0.558

25th percentile:

0.477

Aggregate Multipliers

Domestic, $\beta^{\prime}(I-B)^{-1} 1$

1.61

Imports, $1 /\left(1-\beta^{\prime}(I-B)^{-1} \lambda\right)$

1.03

Overall, $\tilde{\mu}$

Actual intermediate goods share:

0.434

"As if" intermediate goods share:

0.394

Note: Except where noted, staistics are reported for the overall inputoutput matrix of $\sigma_{i j}+\lambda_{i j}$. 
two-thirds of its revenue to intermediate goods, while even the industry at the 25th percentile pays nearly half. Along these lines, it is worth noting that even though just $0.13 \%$ of the elements of the input-output matrix exceed 10 percent, this is still 288 elements over all — on average about once for every two sectors. Similarly, 83 of the entries are greater than 20 percent. As the bottom of the table shows, the overall intermediate goods share for the U.S. economy is about $43.4 \%$ : service industries are more important as a share of value-added, and these industries have lower intermediate goods shares.

The last part of the table computes the aggregate multiplier using the 6-digit input-output data. The overall mutliplier is 1.65 . This number is the product of a domestic multiplier of 1.61 (that would obtain if no intermediate goods were imported), and an import multiplier of 1.03. Imports are relatively unimportant in the multiplier.

To what extent is the simple $\frac{1}{1-\bar{\sigma}}$ formula accurate? The multiplier of 1.65 would result from this formula if the intermediate goods share were 0.394 . In fact, the intermediate goods share using this 6 -digit data is 0.434 . This simple aggregate formula appears to give a good approximation to the result found by computing the 480x480 Leontief inverse, although there is a small degree of dilution: applying the formula to the 0.434 share suggests a multiplier that overstates the truth by about ten percent.

\subsection{The OECD Input-Output Data, 48 Industries}

The 2006 edition of the OECD Input-Output Database contains input-output data for 35 countries and 48 industries, typically for the year 2000. In addition to covering OECD countries, the data also include some poor and middle-income countries, such as China, India, Argentina, Brazil, and Russia.

Figure 6 shows the input-output matrix for the United States at this higher level of aggregation. The pattern at the more detailed level of aggregation of a sparse matrix with a strong diagonal and just a few goods that are used widely is repeated at this higher level of aggregation. 
Figure 6: The U.S. Input-Output Matrix, 2000 (48 Industries)

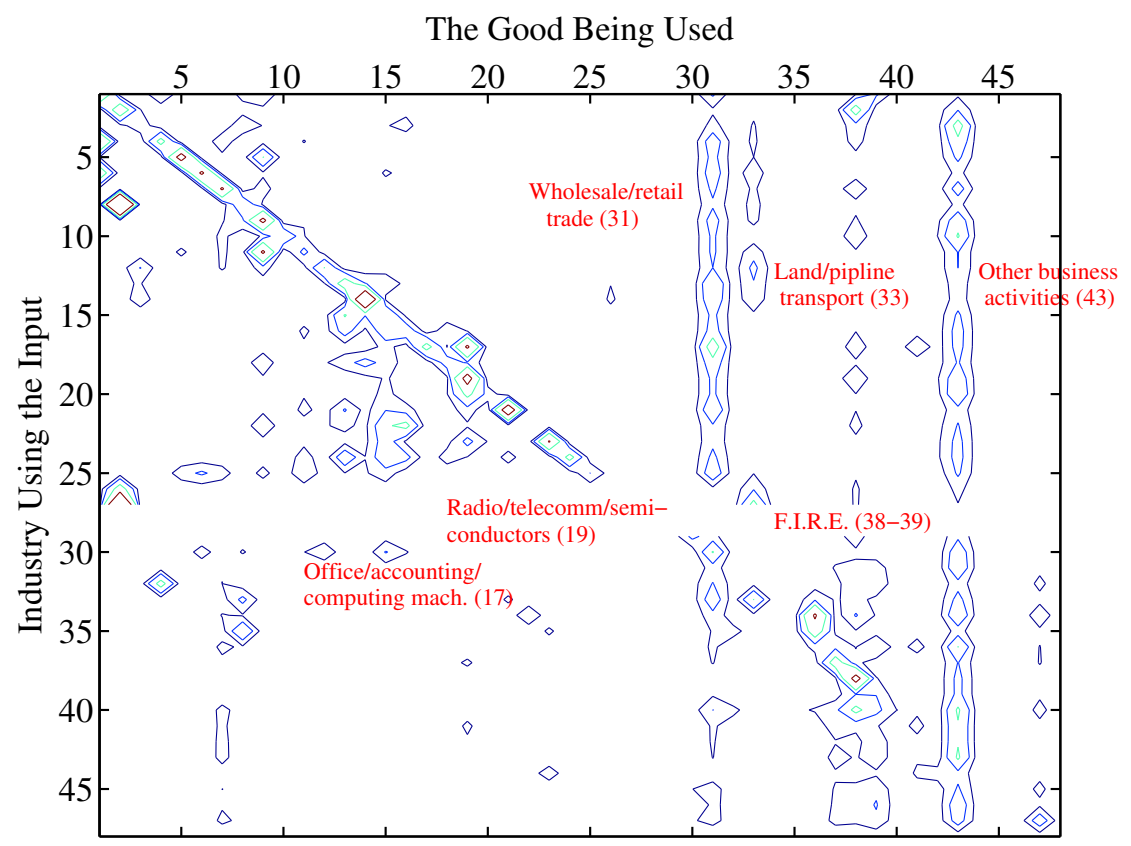

Note: Note: The plot shows the matrix $\left[\sigma_{i j}+\lambda_{i j}\right]$, that is, the matrix of intermediate good shares for 48 industries. A contour plot method is used, showing only those shares greater than 2\%, 5\%, 10\% and 20\%. Source: OECD 2006 database. 
Figure 7: Input-Output Matrix in Japan and China (48 Industries)

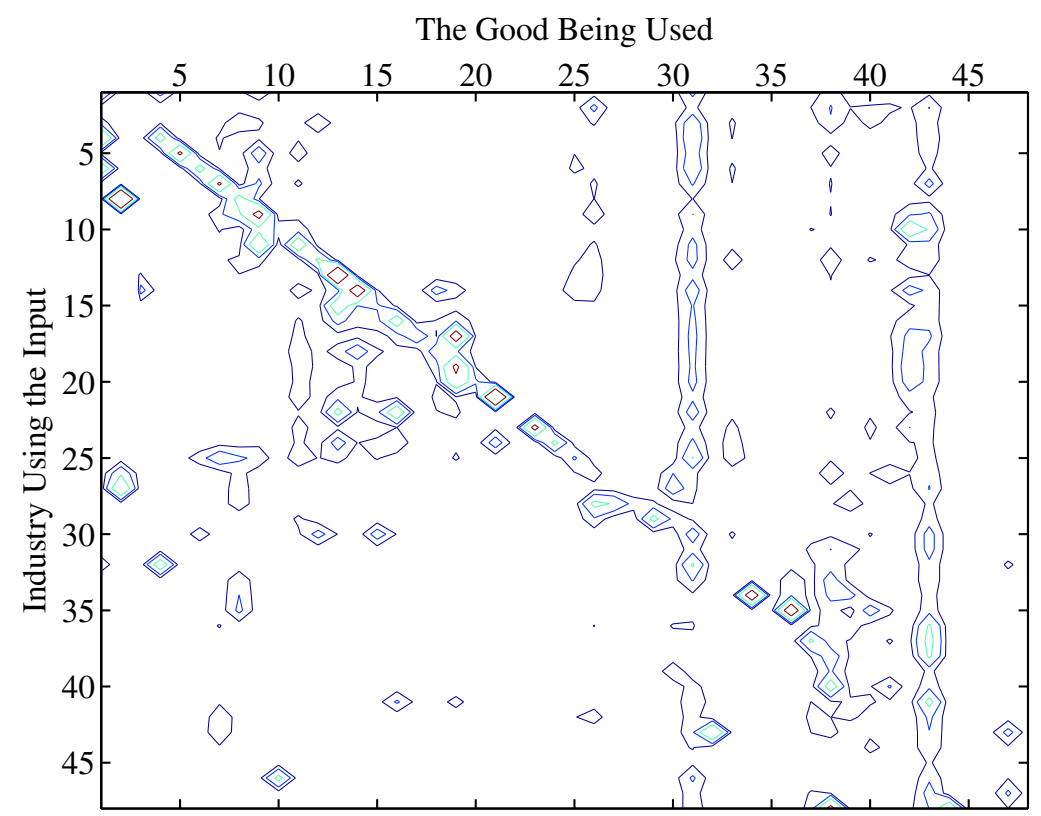

(a) Japan

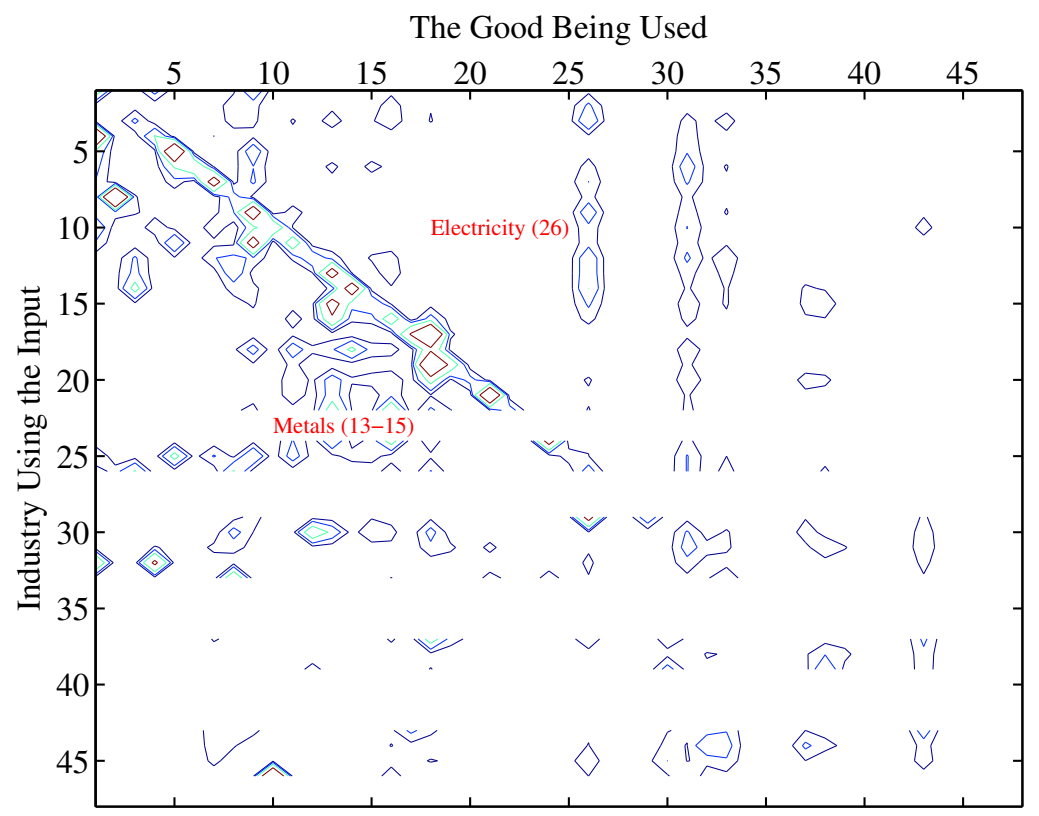

(b) China 
One of the nice features of the OECD data is that we can consider the question of how much the input-output structure of an economy differs across countries. The general and perhaps surprising answer that one obtains is "not much." Figure 7 shows the input-output matrix for two countries, Japan and China, as an example.

The matrix for Japan looks very much like the matrix for the United States. This is true more generally, especially for the richer countries in the data set. But it is even true for the poorer countries. The input-output matrix for China is perhaps the most different from the United States, but the overall structure is still similar. Electricity shows up as being noticeably more important, and other business activities (which include advertising, accounting, and legal services) as somewhat less important. These are the main differences.

The first column of Table 3 makes these comparisons more systematically. It shows the fraction of elements in the input-output matrix that differ by more than 0.02 from the corresponding elements in the U.S. input-output matrix. Just over 16 percent of the elements exceed this difference in China's input-output matrix, while the corresponding number for Japan is about 9 percent. For this level of the cutoff, the average across the 35 countries is 11 percent. If we lower the cutoff to 0.01 , the typical country has differences of this magnitude in just over 20 percent of the cells. If we raise the cutoff to 0.05 , the average across countries is 3.9 percent of cells.

Figure 8 shows the aggregate multipliers, $\tilde{\mu}$ for the 35 countries in our sample. The average value for the multiplier in this sample is about 1.9. It ranges from a high of 2.53 in China to lows of 1.51 in Greece and 1.59 in India. Interestingly, China and India are two of the poorest countries in the sample, and they have widely different multipliers. The multiplier for the United States using this data works out to be 1.77, slightly higher than what we found in the 6-digit data.

Table 3 shows these multipliers in more detail, including the contribution from imported intermediate goods as well as the aggregate intermediate goods share and the "as if" share that corresponds to the multiplier computed using the Leontief inverse. The simple approximation of "one over one minus the intermediate goods share" does a very good job of approximating the true multiplier. 
Table 3: The Multiplier across a Range of Countries (48 Industries)

\begin{tabular}{|c|c|c|c|c|c|c|}
\hline Country & $\begin{array}{c}\text { Fraction } \\
>.02 \\
\text { Different }\end{array}$ & Domestic & $\begin{array}{l}\text { ltipliers - } \\
\text { Import }\end{array}$ & Total & $\begin{array}{c}\text { Overall } \\
\text { Interm. } \\
\text { Share }\end{array}$ & $\begin{array}{l}\text { "As If" } \\
\text { Interm. } \\
\text { Share }\end{array}$ \\
\hline China & 0.161 & 2.21 & 1.14 & 2.53 & 0.63 & 0.61 \\
\hline Czech Republic & 0.115 & 1.75 & 1.38 & 2.41 & 0.62 & 0.58 \\
\hline Slovak Republic & 0.114 & 1.68 & 1.38 & 2.31 & 0.61 & 0.57 \\
\hline Hungary & 0.107 & 1.53 & 1.38 & 2.10 & 0.60 & 0.52 \\
\hline Korea & 0.109 & 1.72 & 1.22 & 2.10 & 0.58 & 0.52 \\
\hline Belgium & 0.104 & 1.60 & 1.30 & 2.09 & 0.57 & 0.52 \\
\hline New Zealand & 0.114 & 1.77 & 1.15 & 2.03 & 0.54 & 0.51 \\
\hline Poland & 0.120 & 1.73 & 1.17 & 2.02 & 0.53 & 0.50 \\
\hline Finland & 0.101 & 1.63 & 1.21 & 1.98 & 0.53 & 0.50 \\
\hline United Kingdom & 0.096 & 1.72 & 1.14 & 1.95 & 0.51 & 0.49 \\
\hline Portugal & 0.112 & 1.63 & 1.18 & 1.93 & 0.52 & 0.48 \\
\hline Australia & 0.104 & 1.71 & 1.11 & 1.89 & 0.49 & 0.47 \\
\hline Sweden & 0.096 & 1.57 & 1.21 & 1.89 & 0.51 & 0.47 \\
\hline Netherlands & 0.096 & 1.54 & 1.22 & 1.89 & 0.51 & 0.47 \\
\hline Ireland & 0.135 & 1.35 & 1.39 & 1.88 & 0.53 & 0.47 \\
\hline Spain & 0.099 & 1.59 & 1.17 & 1.87 & 0.50 & 0.46 \\
\hline Italy & 0.094 & 1.62 & 1.15 & 1.86 & 0.50 & 0.46 \\
\hline Austria & 0.085 & 1.51 & 1.22 & 1.84 & 0.48 & 0.46 \\
\hline Taiwan & 0.104 & 1.53 & 1.20 & 1.83 & 0.52 & 0.45 \\
\hline Japan & 0.092 & 1.75 & 1.05 & 1.83 & 0.48 & 0.45 \\
\hline Brazil & 0.109 & 1.69 & 1.07 & 1.81 & 0.48 & 0.45 \\
\hline Switzerland & 0.151 & 1.54 & 1.17 & 1.81 & 0.49 & 0.45 \\
\hline Russia & 0.242 & 1.63 & 1.11 & 1.80 & 0.47 & 0.45 \\
\hline Germany & 0.104 & 1.58 & 1.14 & 1.80 & 0.49 & 0.44 \\
\hline France & 0.104 & 1.63 & 1.10 & 1.79 & 0.48 & 0.44 \\
\hline Canada & 0.087 & 1.52 & 1.18 & 1.79 & 0.48 & 0.44 \\
\hline United States & 0.000 & 1.68 & 1.05 & 1.77 & 0.46 & 0.44 \\
\hline Norway & 0.098 & 1.53 & 1.15 & 1.75 & 0.46 & 0.43 \\
\hline Indonesia & 0.133 & 1.52 & 1.14 & 1.73 & 0.49 & 0.42 \\
\hline Denmark & 0.098 & 1.48 & 1.15 & 1.70 & 0.43 & 0.41 \\
\hline Israel & 0.106 & 1.49 & 1.10 & 1.63 & 0.41 & 0.39 \\
\hline Argentina & 0.096 & 1.53 & 1.06 & 1.62 & 0.42 & 0.38 \\
\hline Turkey & 0.114 & 1.43 & 1.11 & 1.59 & 0.41 & 0.37 \\
\hline India & 0.153 & 1.49 & 1.07 & 1.59 & 0.44 & 0.37 \\
\hline Greece & 0.114 & 1.37 & 1.10 & 1.51 & 0.38 & 0.34 \\
\hline Average & 0.110 & 1.61 & 1.17 & 1.88 & 0.50 & 0.46 \\
\hline
\end{tabular}

Note: The first column reports the fraction of entries in a country's input-output matrix that differ from those in the U.S. matrix by more than 0.02 . 
Figure 8: The Multiplier across a Range of Countries (48 Industries)

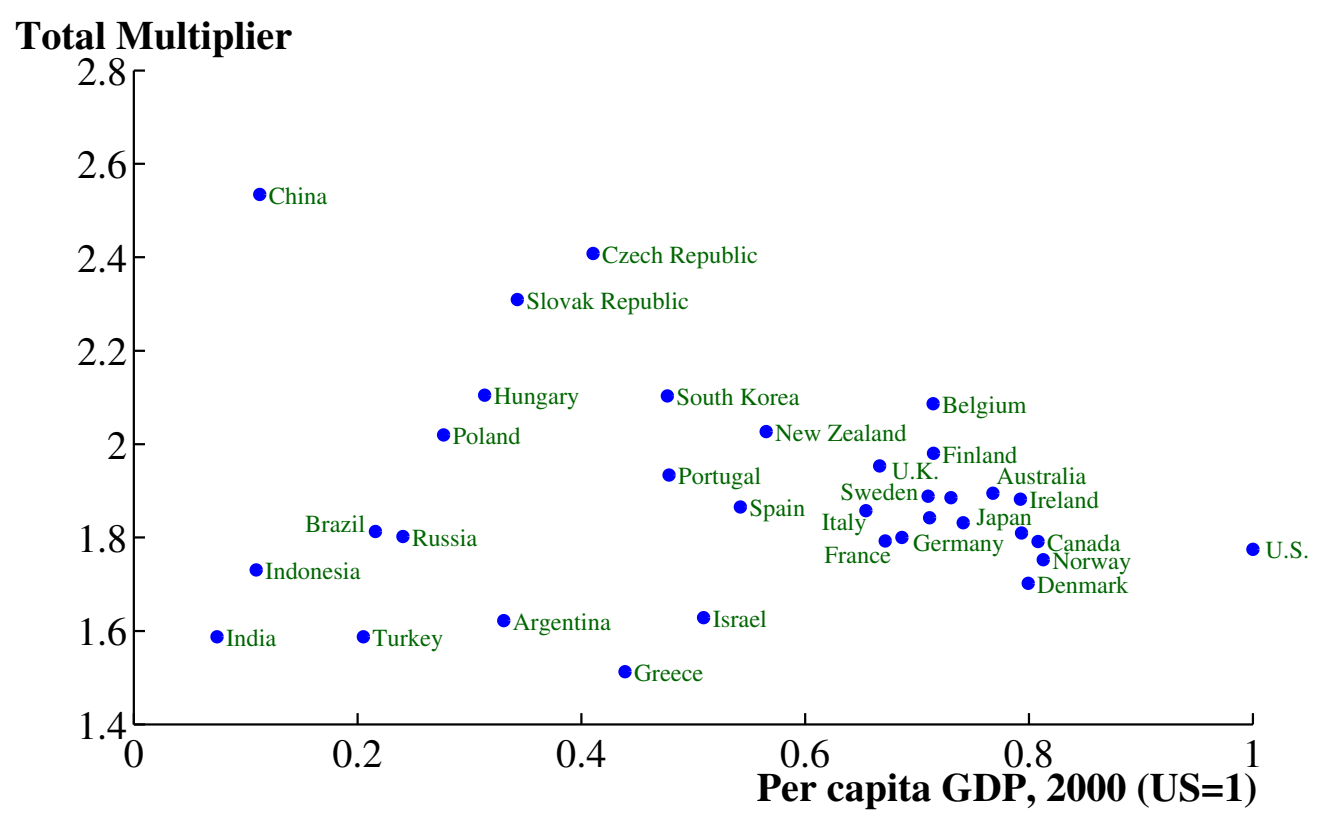

The figure plots the value of $\tilde{\mu}$ computed for each country against 2000 per capita GDP from the Penn World Tables.

\subsection{Take-away from the IO Data}

What do we learn from the input-output data? Three things, I think. First, the common $1 / 1-\bar{\sigma}$ formula that emerges from simple models of intermediate goods is remarkably robust: more careful analysis with full input-output structures across a range of economies suggest that the basic multiplier from simple models carries over quite well. Working with simpler models, then, may be appropriate.

Second, there is a surprising degree of similarity in these matrices across countries. This is surprising in that one might have expected significant differences both for technological reasons and for reasons related to misallocation. On the technological front, countries at different levels of development presumably produce with different technologies, and one might have expected to see this more strongly in the input-output structure of these economies. This is particularly true given the 
specialization arguments associated with international trade.

On the misallocation front, it should be appreciated that many distortions that might be present would show up by changing observed factor shares, even if the underlying technologies were the same. One way to see that is to recall the first-order condition in a simple neoclassical growth model with Cobb-Douglas production: $(1-\tau) \alpha \frac{Y}{K}=r$. Firms rent capital until the post-distortion marginal product falls to equal the rental rate. But in this case, $r K / Y=\alpha(1-\tau)$, so the observed capital share will differ from the techological parameter by the distortion rate.

This in turn has important implications. There is a fundamental identification problem: we see data on observed intermediate goods shares, and we do not know how to decompose that data into distortions and differences in technologies. This identification problem is not solved in anything I have done. Instead, I've simply shown that the observed spending shares are remarkably similar across countries.

My tentative conclusion given this fact is that the misallocation across 4-digit sectors is not particularly large in this sample of countries. Without solving the basic identification problem, however, this conclusion must remain tentative. One useful way to check this would be to assume the U.S. input-output structure measures the true technology for all countries, and to use observed spending shares on intermediate goods to measure the distortions that apply on average across the 4-digit sectors. This would be a valuable exercise. Of course, one could certainly question the assumption that the underlying technologies in all countries are the U.S. factor shares. Moreover, this approach would not measure the distortions that apply within each sector, which may be quite important in practice. Redoing the Hsieh and Klenow (2009) analysis using gross output and intermediate goods within sectors for China and India (and other countries) would also be valuable.

\section{Conclusion}

One of the most exciting directions in the growth literature in recent years has been the recognition that the misallocation of resources at the micro level can aggregate up to look like differences in total factor productivity. Quantifying these effects in 
novel ways, two examples being the extensive use of firm-level data and the exploration of input-output tables, is yielding new insights on why some countries are so much richer than others and likely has a promising future.

\section{A Appendix: Proofs of the Propositions}

Proof of Proposition 1. Solving for $Y$ and $C$

We begin by considering the profit maximization problems for the final goods and intermediate goods firms. For the final goods firms, recall that the problem is

$$
\max _{\left\{c_{i}\right\}} c_{1}^{\beta_{1}} \cdot \ldots \cdot c_{N}^{\beta_{N}}-\sum_{i=1}^{N} p_{i} c_{i}
$$

This yields a FOC where the spending shares are the exponents:

$$
\frac{p_{i} c_{i}}{Y}=\beta_{i}
$$

Next, consider the intermediate firms:

$$
\begin{gathered}
\max _{\left\{d_{i j}, m_{i j}\right\}, K_{i}, H_{i}}\left(1-\tau_{i}\right) p_{i} A_{i}\left(K_{i}^{\alpha_{i}} H_{i}^{1-\alpha_{i}}\right)^{1-\sigma_{i}-\lambda_{i}} d_{i 1}^{\sigma_{i 1}} d_{i 2}^{\sigma_{i 2}} \cdot \ldots \cdot d_{i N}^{\sigma_{i N}} m_{i 1}^{\lambda_{i 1}} m_{i 2}^{\lambda_{i 2}} \cdot \ldots \cdot m_{i N}^{\lambda_{i N}} \\
-\sum_{j=1}^{N} p_{j} d_{i j}-\sum_{j=1}^{N} \bar{p}_{j} m_{i j}-r K_{i}-w H_{i}
\end{gathered}
$$

The first order conditions for this problem are

$$
\begin{gathered}
\left(1-\tau_{i}\right) \alpha_{i}\left(1-\sigma_{i}-\lambda_{i}\right) \frac{p_{i} Q_{i}}{K_{i}}=r \\
\left(1-\tau_{i}\right)\left(1-\alpha_{i}\right)\left(1-\sigma_{i}-\lambda_{i}\right) \frac{p_{i} Q_{i}}{H_{i}}=w \\
\left(1-\tau_{i}\right) \sigma_{i j} \frac{p_{i} Q_{i}}{d_{i j}}=p_{j} \\
\left(1-\tau_{i}\right) \lambda_{i j} \frac{p_{i} Q_{i}}{m_{i j}}=\bar{p}_{j} .
\end{gathered}
$$


Now we are ready to use these FOCs to solve for some allocations. Begin with the resource constraint for sector $j$ :

$$
c_{j}+\sum_{i=1}^{N} d_{i j}=Q_{j}
$$

Now use equation (21) to get rid of $d_{i j}$ and rearrange slightly to get:

$$
p_{j} c_{j}+\sum_{i=1}^{N}\left(1-\tau_{i}\right) \sigma_{i j} p_{i} Q_{i}=p_{j} Q_{j}
$$

Finally, from the first-order condition for the final goods firm that $p_{j}=\beta_{j} Y / c_{j}$. Using this expression for $p_{j}$ and canceling $Y$ from both sides of the equation gives

$$
\beta_{j}+\sum_{i=1}^{N}\left(1-\tau_{i}\right) \sigma_{i j} \frac{\beta_{i} Q_{i}}{c_{i}}=\frac{\beta_{j} Q_{j}}{c_{j}}
$$

Now, define $v_{j} \equiv \frac{\beta_{j} Q_{j}}{c_{j}}$ and let $v$ denote the $N \times 1$ vector of $v_{j}$. Then we can stack the $N$ equations in (23) to get an equation involving vectors and a matrix:

$$
\beta+\bar{B}^{\prime} v=v
$$

where $\beta$ is the $N \times 1$ vector of final goods exponents and $\bar{B}$ is the $N \times N$ matrix of intermediate goods shares adjusted for taxes: a typical element is $\left(1-\tau_{i}\right) \sigma_{i j}$. This equation solves easily to give

$$
v^{*}=\left(I-\bar{B}^{\prime}\right)^{-1} \beta \equiv \gamma
$$

Notice that this defines the solution for $\beta_{j} Q_{j} / c_{j}$ as $\gamma_{j}$. It is easy to show in fact that these elements are also the solution for $p_{j} Q_{j} / Y=\gamma_{j}$, so that the $\gamma_{j}$ terms are the "Domar" weights - the ratio of total spending on intermediate good $j$ to $Y$.

At this point, we can use this solution to get useful expressions for $d_{i j}$ and $m_{i j}$ as well. Equation (18) implies that $\frac{p_{i}}{p_{j}}=\frac{\beta_{i}}{\beta_{j}} \cdot \frac{c_{j}}{c_{i}}$. Substituting this into the FOC for $d_{i j}$ 
in (21) leads to

$$
d_{i j}=\left(1-\tau_{i}\right) \sigma_{i j} \frac{\gamma_{i}}{\gamma_{j}} \cdot Q_{j}
$$

Similarly, $m_{i j}$ satisfies

$$
m_{i j}=\left(1-\tau_{i}\right) \lambda_{i j} \gamma_{i} Y / \bar{p}_{j}
$$

The FOCs for $K_{i}$ and $H_{i}$ similarly yield

$$
\frac{K_{i}}{K}=\frac{\left(1-\tau_{i}\right)\left(1-\sigma_{i}-\lambda_{i}\right) \alpha_{i} \gamma_{i}}{\sum_{i}\left(1-\tau_{i}\right)\left(1-\sigma_{i}-\lambda_{i}\right) \alpha_{i} \gamma_{i}} \equiv \bar{\theta}_{K i}
$$

and

$$
\frac{K_{i}}{K}=\frac{\left(1-\tau_{i}\right)\left(1-\sigma_{i}-\lambda_{i}\right)\left(1-\alpha_{i}\right) \gamma_{i}}{\sum_{i}\left(1-\tau_{i}\right)\left(1-\sigma_{i}-\lambda_{i}\right)\left(1-\alpha_{i}\right) \gamma_{i}} \equiv \bar{\theta}_{H i} .
$$

In this expression, the "bars" over the $\theta$ s denote that these expressions include the $\left(1-\tau_{i}\right)$ terms in the numerator; this is useful below.

Now we can substitute the expressions in (26) through (29) back into the main production function for intermediate goods. Factoring out the $1-\tau_{i}$ terms (and letting the $\left.\theta_{K i} \equiv \bar{\theta}_{K i} /\left(1-\tau_{i}\right)\right)$ gives

$Q_{i}=A_{i}\left(1-\tau_{i}\right)\left(\left(\theta_{K i} K\right)_{i}^{\alpha}\left(\theta_{H i} H\right)^{1-\alpha_{i}}\right)^{1-\sigma_{i}-\alpha_{i}} \cdot \Pi_{j=1}^{N}\left(\sigma_{i j} Q_{j} \gamma_{i} / \gamma_{j}\right)^{\sigma_{i j}} \cdot \Pi_{j=1}^{N}\left(\lambda_{i j} \gamma_{i} Y / \bar{p}_{j}\right)^{\lambda_{i j}}$.

Taking logs of this expression, stacking into a vector, and using much of the notation in Table 1 gives

$$
q=\bar{a}+\omega_{q}+\delta_{K} \log K+\delta_{H} \log H+B q+\lambda \log Y,
$$

where $q$ is the vector with typical element $\log Q_{i}, \bar{a}$ is a vector with typical element $\log A_{i}\left(1-\tau_{i}\right)$, and $B$ is the matrix of $\sigma_{i j}$ (see the table for the rest of the notation).

This equation can be solved to yield

$$
q=(I-B)^{-1}\left(\bar{a}+\omega_{q}+\delta_{K} \log K+\delta_{H} \log H+\lambda \log Y\right)
$$

We will use this expression shortly. First, though, we go back to the final goods 
production function. Recall that $c_{i}=\beta_{i} Q_{i} / \gamma_{i}$. Taking logs and stacking into a vector, this gives

$$
c=\omega_{c}+q
$$

where $\omega_{c}$ is a vector with typical element $\log \beta_{i} / \gamma_{i}$ and $c$ denotes the vector of $\log c_{i}$.

Then, from the final goods production function and using the vector notation, $\log Y=\beta^{\prime} c=\beta^{\prime} \omega_{c}+\beta^{\prime} q$.

We are now at the last step. Substitute (32) into this last expression to get

$$
\log Y=\beta^{\prime} \omega_{c}+\beta^{\prime}(I-B)^{-1}\left(\bar{a}+\omega_{q}+\delta_{K} \log K+\delta_{H} \log H+\lambda \log Y\right)
$$

Let $A_{i} \equiv A \eta_{i}$. This last equation can then be solved for $\log Y$ to yield

$$
\log Y=\tilde{\mu} \log A+\tilde{\alpha} \log K+(1-\tilde{\alpha}) \log H+\log \epsilon
$$

where the notation used is that in Table 1.

The expression for consumption comes from using balanced trade and the expression for $m_{i j}$ given in (22).

Proof of Proposition 2. The Multiplier in a Special Case

In matrix notation, the assumption that all sectors have a cumulative domestic intermediate goods share of $\hat{\sigma}$ is simply $B \mathbf{1}=\hat{\sigma} \mathbf{1}$. This implies the following:

$$
\begin{aligned}
(I-B) \mathbf{1} & =(1-\hat{\sigma}) \mathbf{1} \\
\mathbf{1} & =(I-B)^{-1} \mathbf{1} \cdot(1-\hat{\sigma}) \\
1=\beta^{\prime} \mathbf{1} & =\beta^{\prime}(I-B)^{-1} \mathbf{1} \cdot(1-\hat{\sigma}) \\
\Rightarrow & \beta^{\prime}(I-B)^{-1} \mathbf{1}=\frac{1}{1-\hat{\sigma}}
\end{aligned}
$$

Similarly, $\beta^{\prime}(I-B)^{-1} \lambda=\frac{\hat{\lambda}}{1-\hat{\sigma}}$. Therefore

$$
\mu^{\prime} \mathbf{1}=\frac{\beta^{\prime}(I-B)^{-1} \mathbf{1}}{1-\beta^{\prime}(I-B)^{-1} \lambda}=\frac{1}{1-(\hat{\sigma}+\hat{\lambda})}=\frac{1}{1-\bar{\sigma}} .
$$


Proof of Proposition 3. Symmetry and Distortions

The key step in solving the model is to use the same general result as in the previous proposition: if a matrix $X$ has rows that sum to the same value, $\bar{x}$, then $(I-X)^{-1} \mathbf{1}=\mathbf{1} \cdot \frac{1}{1-\bar{x}}$. In this case, this result is used in computing $\gamma=\left(I-\bar{B}^{\prime}\right)^{-1} \beta$, where $\beta_{i}=1 / N$. Because of the symmetry, one obtains

$$
\gamma_{j}=\hat{\gamma} \equiv \frac{1 / N}{1-\sigma(1-\bar{\tau})}
$$

Substituting this result into the FOCs, one gets

$$
\begin{gathered}
d_{i j}=(1-\bar{\tau}) \hat{\sigma} Q_{j} / N \\
m_{i j}=(1-\bar{\tau}) \hat{\lambda} / N \hat{\gamma} Y / \bar{p}_{j}
\end{gathered}
$$

as well as $K_{i} / K=H_{i} / H=1 / N$.

Using these condition to compute the allocation terms, one obtains

$$
\omega_{q i}=-(1-\hat{\sigma}-\hat{\lambda}) \log (1-\bar{\tau})-\hat{\lambda} \log (1-\hat{\sigma}(1-\bar{\tau}))+\text { Constant }
$$

where the constant does not depend on $\bar{\tau}$ or on the sector $i$. In addition, $\beta^{\prime} \omega_{c}=$ $\log (1-\hat{\sigma}(1-\bar{\tau}))$.

Following the definitions in Table 1, these expressions can be combined to yield the allocation term:

$$
\omega=\log (1-\hat{\sigma}(1-\bar{\tau}))-\log (1-\bar{\tau})+\text { Constant }
$$

for some other constant that does not depend on $\bar{\tau}$.

Substituting this into the definition of $\epsilon$ gives

$$
\log \epsilon=\log (1-\hat{\sigma}(1-\bar{\tau}))+\frac{\hat{\sigma}+\hat{\lambda}}{1-(\hat{\sigma}+\hat{\lambda})} \log (1-\bar{\tau})+\text { Constant }
$$


Furthermore, $\log Y$ will have the same form.

Finally, we need to get the expression for GDP, $C$. Recall that because of balanced trade,

$$
C=Y\left(1-\sum_{i=1}^{N} \sum_{j=1}^{N}\left(1-\tau_{i}\right) \gamma_{i} \lambda_{i j}\right)
$$

Similar arguments to those above give

$$
C=Y\left(\frac{1-(\hat{\sigma}+\hat{\lambda})(1-\bar{\tau})}{1-\hat{\sigma}(1-\bar{\tau})}\right)
$$

Substituting this into the expression for $Y$ (or rather $\log \epsilon$ ) above completes the proof.

Proof of Proposition 4. Symmetry with Random Distortions

This proof follows that for Proposition 3 fairly closely. The main exception turns out to be in getting the solution for $\mu^{\prime} \ell$, where $\ell$ denotes the $N \times 1$ vector with typical element $\log \left(1-\tau_{i}\right)$. This proceeds as follows. Using the fact that $\beta_{i}=1 / N$

$$
\mu^{\prime} \ell=\frac{1-\hat{\sigma}}{1-(\hat{\sigma}+\hat{\lambda})} \cdot \frac{1}{N} \cdot \mathbf{1}^{\prime}(I-B)^{-1} \ell
$$

The key step is then to show that $\mathbf{1}^{\prime}(I-B)^{-1}=\frac{1}{1-\hat{\sigma}} \cdot \mathbf{1}^{\prime}$. This can be shown as follows. Let $\sigma$ denote an $N \times 1$ vector where each element is $\hat{\sigma}$. Then, since $B$ is an entire matrix of $\hat{\sigma}$, it follows that

$$
\mathbf{1}^{\prime} B=\sigma^{\prime}
$$

Then

$$
\mathbf{1}^{\prime}-\mathbf{1}^{\prime} B=\mathbf{1}^{\prime}-\sigma^{\prime}
$$

and therefore

$$
\mathbf{1}^{\prime}(I-B)=(1-\hat{\sigma}) \mathbf{1}^{\prime}
$$

Post-multiplying by $(I-B)^{-1}$ and rearranging gives the result we wanted: $\mathbf{1}^{\prime}(I-$ $B)^{-1}=\frac{1}{1-\hat{\sigma}} \cdot \mathbf{1}^{\prime}$. Once this is substituted into equation (36), one gets the expected 
result that

$$
\mu^{\prime} \ell=\frac{1}{1-(\hat{\sigma}+\hat{\lambda})} \cdot \frac{1}{N} \sum_{i} \log \left(1-\tau_{i}\right)
$$

Following the same arguments used in proving Proposition 3, one gets

$\log C=\log (1-(\hat{\sigma}+\hat{\lambda})(1-\bar{\tau}))-\log (1-\bar{\tau})+\frac{1}{1-(\hat{\sigma}+\hat{\lambda})} \cdot \frac{1}{N} \sum_{i} \log \left(1-\tau_{i}\right)+$ Constant.

The rest of the proposition follows naturally from the log normal assumptions on $1-\tau_{i}$.

\section{References}

Acemoglu, Daron, Asuman Ozdaglar, and Alireza Tahbaz-Salehi, "Cascades in Networks and Aggregate Volatility,” NBER Working Papers 16516, National Bureau of Economic Research, Inc November 2010.

_ , Simon Johnson, and James A. Robinson, "Reversal of Fortune: Geography and Institutions in the Making of the Modern World Income Distribution," Quarterly Journal of Economics, 2002, 117 (4), 1231-1294.

_ , _ , and _ , "Institutions as a Fundamental Cause of Long-Run Growth," in Philippe Aghion and Steven Durlauf, eds., Handbook of Economic Growth, Vol. 1 of Handbook of Economic Growth, Elsevier, April 2005, chapter 6, pp. 385-472.

Alfaro, Laura, Andrew Charlton, and Fabio Kanczuk, "Firm-Size Distribution and CrossCountry Income Differences," NBER Working Paper 14060, June 2008.

Arbex, Marcelo and Fernando S. Perobelli, "Solow Meets Leontief: Economic Growth and Energy Consumption,” Energy Economics, January 2010, 32 (1), 43-53.

Banerjee, Abhijit V. and Esther Duflo, "Growth Theory through the Lens of Development Economics," in Philippe Aghion and Steven A. Durlauf, eds., Handbook of Economic Growth, New York: North Holland, 2005, pp. 473-552.

Bartelsman, E.J., J. Haltiwanger, and S. Scarpetta, "Cross-Country Differences in Productivity: The Role of Allocation and Selection,” NBER Working Paper 15490, 2009. 
Basu, Susanto, "Intermediate Goods and Business Cycles: Implications for Productivity and Welfare," American Economic Review, June 1995, 85 (3), 512-531.

_ , John Fernald, Jonas Fisher, and Miles Kimball, "Sector-Specific Technical Change," April 2010. Federal Reserve Bank of San Francisco manuscript.

Buera, Francisco J. and Yongseok Shin, "Financial Frictions and the Persistence of History: A Quantitative Exploration,” Manuscript, Washington University in St. Louis, 2008.

Caselli, Francesco and Nicola Gennaioli, “Dynastic Management,” December 2005. London School of Economics working paper.

Chari, V.V., Pat Kehoe, and Ellen McGrattan, “The Poverty of Nations: A Quantitative Investigation," 1997. Working Paper, Federal Reserve Bank of Minneapolis.

_ ,_ , and _ , “Business Cycle Accounting,” Econometrica, May 2007, 75 (3), 781-836.

Ciccone, Antonio, "Input Chains and Industrialization," Review of Economic Studies, July 2002, 69 (3), 565-587.

Cogley, Timothy and James M. Nason, "Output Dynamics in Real-Business-Cycle Models," American Economic Review, June 1995, 85 (3), 492-511.

Conley, Timothy G. and Bill Dupor, “A Spatial Analysis of Sectoral Complementarity,” Journal of Political Economy, April 2003, 111 (2), 311-352.

Diamond, Peter A. and James A. Mirrlees, "Optimal Taxation and Public Production I: Production Efficiency," American Economic Review, March 1971, 61 (1), 8-27.

Dupor, Bill, "Aggregation and irrelevance in multi-sector models," Journal of Monetary Economics, April 1999, 43 (2), 391-409.

Easterly, William, “How Much Do Distortions A Growth?," Journal of Monetary Economics, November 1993, 32 (2), 187-212.

Epifani, Paolo and Gino A. Gancia, “Trade, Markup Heterogeneity and Misallocations," CEPR Discussion Papers 7217, C.E.P.R. Discussion Papers March 2009.

Erosa, Andres, Tatyana Koreshkova, and Diego Restuccia, "How Important Is Human Capital? A Quantitative Theory Assessment of World Income Inequality," Review of Economic Studies, October 2010, 77 (4), 1421-1449. 
Foster, Lucia, John Haltiwanger, and Chad Syverson, "Reallocation, Firm Turnover, and Efficiency: Selection on Productivity or Profitability?," American Economic Review, March 2008, 98 (1), 394-425.

Gabaix, Xavier, “The Granular Origins of Aggregate Fluctuations,” 2005. MIT working paper.

Gallup, J.L., J.D. Sachs, and A.D. Mellinger, “Geography and Economic Development," International Regional Science Review, 1999, 22 (2), 179.

Guner, Nezih, Gustavo Ventura, and Yi Xu, "Macroeconomic implications of size-dependent policies," Review of Economic Dynamics, 2008, 11 (4), 721-744.

Hauk, William R. and Romain Wacziarg, "A Monte Carlo Study of Growth Regressions," January 2004. NBER Technical Working Paper No. 296.

Hirschman, Albert O., The Strategy of Economic Development, New Haven, CT: Yale University Press, 1958.

Horvath, Michael T.K., "Cyclicality and Sectoral Linkages: Aggregate Fluctuations from Independent Sectoral Shocks," Review of Economic Dynamics, October 1998, 1 (4), 781-808.

Howitt, Peter, "Endogenous Growth and Cross-Country Income Differences," American Economic Review, September 2000, 90 (4), 829-846.

Hsieh, Chang-Tai and Peter J. Klenow, "Misallocation and Manufacturing TFP in China and India," Quarterly Journal of Economics, 2009, 124 (4), 1403-1448.

Hulten, Charles R., "Growth Accounting with Intermediate Inputs," Review of Economic Studies, 1978, 45 (3), 511-518.

Jones, Charles I., "Intermediate Goods and Weak Links in the Theory of Economic Development," American Economic Journal: Macroeconomics, April 2011, 3 (2), xxx-xxx.

Klenow, Peter J. and Andres Rodriguez-Clare, "Extenalities and Growth,” in Philippe Aghion and Steven Durlauf, eds., Handbook of Economic Growth, Amsterdam: Elsevier, 2005.

Kremer, Michael, "Population Growth and Technological Change: One Million B.C. to 1990,” Quarterly Journal of Economics, August 1993, 108 (4), 681-716.

Lagos, Ricardo, “A Model of TFP,” Review of Economic Studies, 2006, 73 (4), 983-1007. 
Lazear, Edward P., "Performance Pay and Productivity," American Economic Review, 2000, 90 (5), 1346-1361.

Leontief, Wassily, "Quantitative Input and Output Relations in the Economic System of the United States," Review of Economics and Statistics, 1936, 18 (3), 105-125.

Long, John B. and Charles I. Plosser, "Real Business Cycles,” Journal of Political Economy, February 1983, 91 (1), 39-69.

Mankiw, N. Gregory, David Romer, and David Weil, "A Contribution to the Empirics of Economic Growth," Quarterly Journal of Economics, May 1992, 107 (2), 407-438.

Manuelli, Rodolfo and Ananth Seshadri, "Human Capital and the Wealth of Nations," March 2005. University of Wisconsin working paper.

Midrigan, Virgiliu and Daniel Y. Xu, "Finance and Misallocation: Evidence from Plant-Level Data," NBER Working Paper 15647, January 2010.

Moll, Benjamin, "Productivity Losses from Financial Frictions: Can Self-financing Undo Capital Misallocation?," 2010. Princeton University manuscript.

Olson, Mancur, "Big Bills Left on the Sidewalk: Why Some Nations are Rich, and Others Poor," Journal of Economic Perspectives, Spring 1996, 10 (2), 3-24.

Parente, Stephen L. and Edward C. Prescott, "Monopoly Rights: A Barrier to Riches," American Economic Review, December 1999, 89 (5), 1216-1233.

Peters, Michael, "Heterogeneous Mark-Ups and Endogenous Misallocation,” 2009. MIT unpublished manuscript.

Porta, Rafael La and Andrei Shleifer, "The Unofficial Economy and Economic Development," Brookings Papers on Economic Activity, 2008, 2, 275-363.

Quah, Danny T., "Empirics for economic growth and convergence," European Economic Review, 1996, 40 (6), 1353-1375.

Rebelo, Sergio, "Long-Run Policy Analysis and Long-Run Growth," Journal of Political Economy, June 1991, 99, 500-521.

Restuccia, Diego and Richard Rogerson, "Policy Distortions and Aggregate Productivity with Heterogeneous Plants,” Review of Economic Dynamics, October 2008, 11, 707-720. 
Schmitz, James A., "What Determines Productivity? Lessons from the Dramatic Recovery of the US and Canadian Iron Ore Industries following their Early 1980s Crisis," Journal of Political Economy, 2005, 113 (3), 582-625.

Solow, John L., "Interindustry Flows and the Incidence of the Corporate Income Tax," Journal of Public Economics, August 1986, 30 (3), 359-368.

Syverson, Chad, "What Determines Productivity?," NBER Working Paper 15712, January 2010.

Vollrath, Dietrich, "How Important are Dual Economy Effects for Aggregate Productivity?," Journal of Development Economics, March 2009, 88 (2), 325-334.

Yi, Kei-Mu, "Can Vertical Specialization Explain the Growth of World Trade?," Journal of Political Economy, February 2003, 111 (1), 52-102. 